\title{
Identification of Larval Pacific Lampreys (Lampetra tridentata), River Lampreys (L. ayresi), and Western Brook lampreys (L. richardsoni) and Thermal Requirements of Early Life History Stages of Lampreys
}

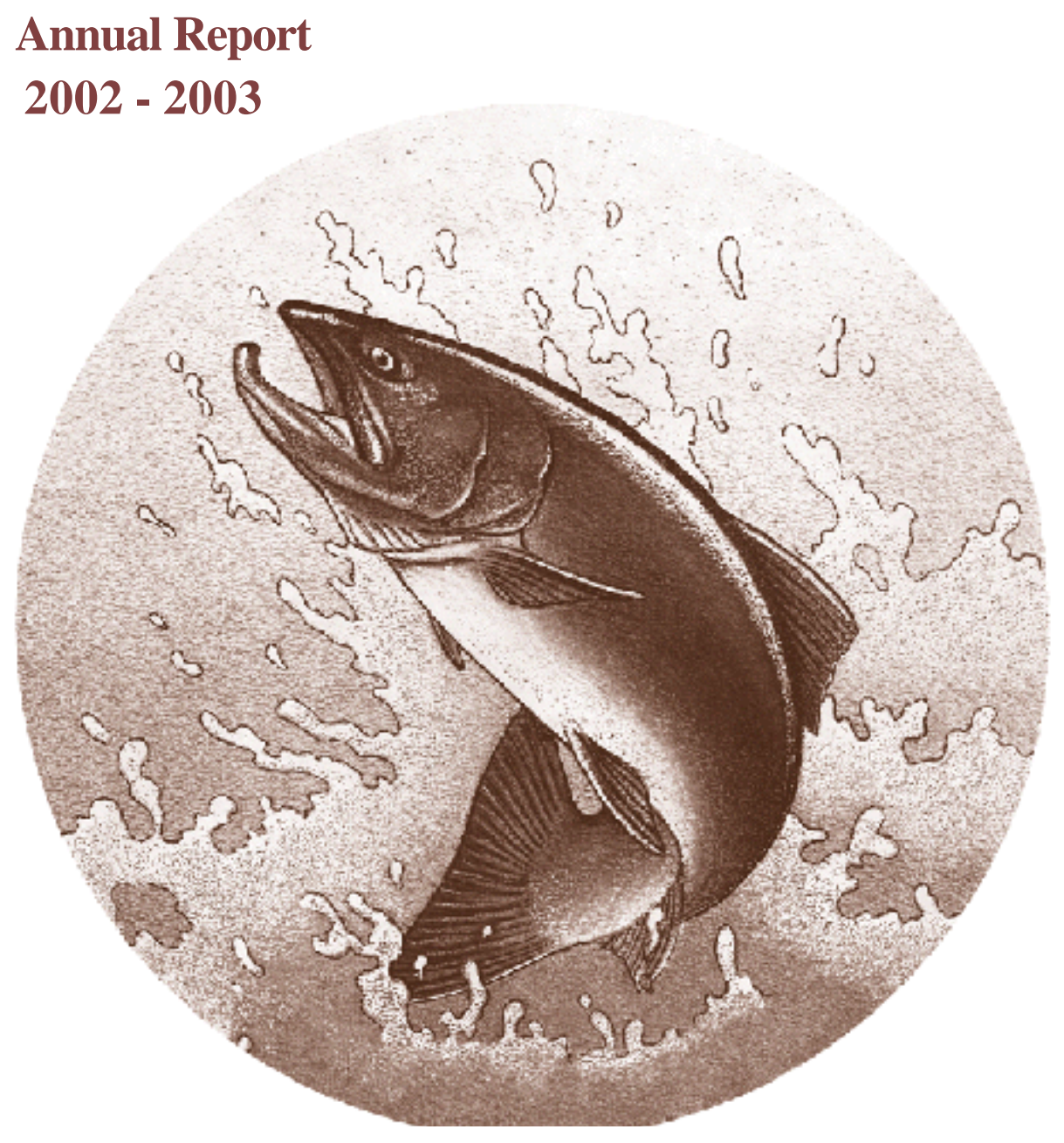


This Document should be cited as follows:

Meeuwig, Michael, Jennifer Bayer, Rebecca Reiche, "Identification of Larval Pacific Lampreys (Lampetra tridentata), River Lampreys (L. ayresi), and Western Brook lampreys (L. richardsoni) and Thermal Requirements of Early Life History Stages of Lampreys", Project No. 2000-02900, 62 electronic pages, (BPA Report DOE/BP-00004695-3)

\author{
Bonneville Power Administration \\ P.O. Box 3621 \\ Portland, Oregon 97208
}

This report was funded by the Bonneville Power Administration (BPA), U.S. Department of Energy, as part of BPA's program to protect, mitigate, and enhance fish and wildlife affected by the development and operation of hydroelectric facilities on the Columbia River and its tributaries. The views in this report are the author's and do not necessarily represent the views of BPA. 
Identification of larval Pacific lampreys (Lampetra tridentata), river lampreys (L. ayresi), and western brook lampreys (L. richardsoni), and thermal requirements of early life history stages of lampreys

Annual report of research 2003

\author{
Prepared by: \\ Michael H. Meeuwig \\ Jennifer M. Bayer \\ and \\ Rebecca A. Reiche \\ U.S. Geological Survey \\ Western Fisheries Research Center \\ Columbia River Research Laboratory \\ 5501A Cook-Underwood Road \\ Cook, WA 98605
}

Prepared for:

U.S. Department of Energy

Bonneville Power Administration

Environment, Fish, and Wildlife Department

P.O. Box 3621

Portland, OR 97208-3621

Project Number 2000-029

Contract Number 00AI23249

January 2004 
Table of contents

\begin{tabular}{|c|c|}
\hline Contents & Page number \\
\hline Title page & 1 \\
\hline Table of contents & 2 \\
\hline Executive summary & 3 \\
\hline Acknowledgements & 5 \\
\hline Introduction & 6 \\
\hline Methods & 9 \\
\hline Laboratory environment & 9 \\
\hline Pigmentation based identification of larval lampreys & 10 \\
\hline Brood stock collection and holding conditions & 11 \\
\hline Morphometric identification of early life stage lampreys & 12 \\
\hline Effects of temperature on early life stage lampreys & 14 \\
\hline Preliminary results and discussion & 16 \\
\hline Pigmentation based identification of larval lampreys & 16 \\
\hline Morphometric identification of early life stage lampreys & 18 \\
\hline Effects of temperature on early life stage lampreys & 19 \\
\hline River lampreys in the Columbia River Basin & 23 \\
\hline Future goals & 29 \\
\hline Literature cited & 30 \\
\hline Tables & 35 \\
\hline Figures & 40 \\
\hline Appendices & 57 \\
\hline
\end{tabular}




\section{Executive summary}

Two fundamental aspects of lamprey biology were examined to provide tools for population assessment and determination of critical habitat needs of Columbia River Basin (CRB) lampreys (the Pacific lamprey, Lampetra tridentata, and the western brook lamprey, $L$. richardsoni). We evaluated the usefulness of current diagnostic characteristics for identification of larval lampreys (i.e., pigment patterns) and collected material for development of meristic and morphometric descriptions of early life stage CRB lampreys, and we determined the effects of temperature on survival and development of early life stage CRB lampreys.

Thirty-one larval lampreys were collected from locations throughout the CRB and transported to the Columbia River Research Laboratory. Lampreys were sampled at six-week intervals at which time they were identified to the species level based on current diagnostic characteristics. Sampling was repeated until lampreys metamorphosed, at which time species identification was validated based on dentition, or until they died, at which time they were preserved for genetic examination. These lampreys were sampled 30 times with two individuals metamorphosing, both of which were consistently identified, and subsequently validated, as Pacific lampreys. Of the remaining lampreys, only one was inconsistently identified (Pacific lamprey in $83 \%$ of the sampling events and western brook lamprey in $17 \%$ of the sampling events). These data suggest that pigmentation patterns do not change appreciably through time.

In 2001 and 2002 we artificially spawned Pacific and western brook lampreys in the laboratory to provide material for meristic and morphometric descriptions. We collected, digitized, preserved, and measured the mean chorion diameter of Pacific and western brook lamprey embryos. Embryos ranged in development from $1 \mathrm{~d}$ post fertilization to just prior to hatch, and were incubated at $14^{\circ} \mathrm{C}$. Mean chorion diameter was greater and more variable for 
Pacific lampreys (mean $\pm \mathrm{SD} ; 1.468 \pm 0.107 \mathrm{~mm}, N=320$ ) than for western brook lampreys $(1.237 \pm 0.064 \mathrm{~mm}, N=280)$. An unpaired $t$-test showed that the difference in mean chorion diameter between species was highly significant $(t=32.788, \mathrm{df}=528.62, P<0.0001)$. For larvae, we collected, digitized, and preserved 156 individuals from each species. Eight homologous landmarks defining a two-cell truss network with two appended triangles were selected for morphometric analyses and species discrimination. A full model discriminant analysis correctly classified $92 \%$ of the Pacific lampreys and $93 \%$ of the western brook lampreys in a classification data set. When applied to a test data set, the classification functions correctly classified $91 \%$ of the Pacific lampreys and $85 \%$ of the western brook lampreys. A backward elimination discriminant analysis removed four variables from the full model, and the reduced model correctly classified $91 \%$ of the Pacific lampreys and $93 \%$ of the western brook lampreys in a classification data set. The reduced model classification functions correctly classified $91 \%$ of the Pacific lampreys and $85 \%$ of the western brook lampreys in a test data set.

In 2001 and 2002 Pacific and western brook lampreys were artificially spawned and resulting progeny were reared in the laboratory at $10^{\circ} \mathrm{C}, 14^{\circ} \mathrm{C}, 18^{\circ} \mathrm{C}$, and $22^{\circ} \mathrm{C}$. The estimated temperature for zero development was $4.85^{\circ} \mathrm{C}$ for Pacific and $4.97^{\circ} \mathrm{C}$ for western brook lampreys. Survival was greatest at $18^{\circ} \mathrm{C}$ followed by $14^{\circ} \mathrm{C}, 10^{\circ} \mathrm{C}$, and $22^{\circ} \mathrm{C}$, with significant differences observed between $22^{\circ} \mathrm{C}$ and other temperatures. Overall survival was significantly greater for western brook than for Pacific lampreys, although the difference in proportion of individuals surviving was only 0.02 . Survival to hatch was significantly greater than survival to the larval stage with a difference of only 0.03 . The proportion of individuals exhibiting abnormalities at the larval stage was greatest at $22^{\circ} \mathrm{C}$ followed by $18^{\circ} \mathrm{C}, 10^{\circ} \mathrm{C}$, and $14^{\circ} \mathrm{C}$, with significant differences observed between $22^{\circ} \mathrm{C}$ and other temperatures. 


\section{Acknowledgements}

Bonneville Power Administration provided funding for this project (Project \#2000-029). We thank individuals at the U.S. Fish and Wildlife Service, National Oceanic and Atmospheric Administration Fisheries, University of Idaho, Idaho Department of Fish and Game, Confederated Tribes of the Umatilla Indian Reservation, and U.S. Geological Survey for their assistance with project activities. We also appreciate the assistance of Debbie Docherty, Project Manager, Bonneville Power Administration. Use of trade or firm names in this document is for reader information only and does not constitute endorsement of a product or service by the U.S. Government. 


\section{Introduction}

Lampreys inhabit temperate regions in both the northern and southern hemispheres. Typically, lampreys spawn in freshwater streams where, after hatching, larval lampreys (ammocoetes) burrow into soft substrate and spend an extended larval period filtering particulate matter from the water column. During this larval period, lampreys are characterized by greatly reduced subcutaneous eyes, reduced fins, unidirectional flow of water from the mouth through the gill pores for filter feeding, and the absence of tooth-like keratin plates (the structures most often used to differentiate lamprey species). After approximately three to seven years (Hardisty and Potter 1971a), lampreys go through a metamorphosis marked by drastic physiological and morphological changes. The resulting juvenile lampreys exhibit fully developed eyes, fins, and characteristic dentition patterns.

Once metamorphosis is complete, lampreys adopt one of two species-specific life history patterns. Resident species remain in streams until sexually mature, at which time they spawn and die. Migratory species move from natal streams into large bodies of freshwater (landlocked) or into marine habitats (anadromous). Both landlocked and anadromous forms use their oral disc to attach to and feed on a variety of aquatic species (Hardisty and Potter 1971b). Lampreys exhibit rapid growth during their predatory phase, which can last from less than one year to greater than two and a half years (Hardisty and Potter 1971b), with the duration ranging greatly among geographical locations and species. Once lampreys have reached an adequate size they cease feeding, migrate into freshwater streams, spawn, and die.

Within the Columbia River Basin (CRB) the occurrence of three native species of lampreys has been documented. Of these species, Pacific lampreys (Lampetra tridentata) and river lampreys (L. ayresi) exhibit a migratory life history pattern, while the western brook 
lamprey (L. richardsoni) exhibits a resident life history pattern. Apart from these generalities, little is known about the biology of lamprey species in the CRB (Kan 1975; Hammond 1979), and what information is available for these species is from work conducted in Canada (Pletcher 1963; Beamish 1980a; Richards 1980; Beamish and Levings 1991). Due to the lack of information on lamprey habitat requirements, population sizes, and community structure, relatively little is known about the status of lamprey species within the CRB. Dam passage data and anecdotal information indicate that Pacific lampreys are in decline in the CRB (Close et al. 1995). The declining trend of Pacific lampreys, along with the ecological, economic, and cultural significance of Pacific lampreys (Kan 1975; NPPC 1994; Close et al. 1995), has stimulated interest in recovery actions within the CRB.

Documenting the distribution and relative abundance of lampreys in tributaries of the Columbia River will help identify factors limiting lamprey populations, identify areas in need of rehabilitation, and help assess the efficacy of management actions. Surveys of larval lampreys may provide an effective means of determining the distribution and abundance of lampreys since larvae are readily collected from rearing areas by electrofishing (Richards et al. 1982). However, within the CRB, larvae of different species often have sympatric or partially overlapping distributions. Therefore, to accurately estimate lamprey distribution and abundance it is necessary to be able to positively identify larvae to the species level. Richards et al. (1982) developed descriptive keys for identifying larvae of lampreys found in British Columbia, Canada. Their study indicates that pigmentation patterns of the tail, head, and tongue precursor can be used to separate Pacific, river, and western brook lampreys. However, use of these identification techniques has proven less diagnostic for larval lampreys in the CRB (USGS, unpublished data), which may be due to the effects of environmental conditions and age on 
pigmentation patterns within and among species (Moyle and Cech 1996). Also, Richards et al. (1982) found that discriminatory pigmentation patterns were not fully developed in the first year of larval life, and were unable to document the timing at which these patterns did develop.

Along with the ability to distinguish among lamprey species, identification of ecological factors limiting lampreys in the CRB is critical to population assessment and recovery efforts. Understanding factors influencing survival during early life stages is particularly important since this period is a critical determinant of recruitment for many fish populations (Houde 1987). Larval fish abundance may be determined by a number of habitat characteristics, including water temperature during early development (Potter and Beamish 1975; Young et al. 1990; Youson et al. 1993). Optimal temperatures for survival and development of sea lampreys (Petromyzon marinus) have been studied extensively (Piavis 1961; McCauley 1963; Holmes and Lin 1994; Rodriguez-Munoz et al. 2001); however, little information is available for other lamprey species. Knowledge of the role of temperature in lamprey early life development will provide managers with a means to assess the suitability of available spawning and rearing habitats, which may be sub-optimal due to alterations in thermal regimes of the Columbia River and its tributaries (Quinn and Adams 1996).

The goal of this project is to address two fundamental aspects of lamprey biology in order to provide tools for lamprey population assessment and determination of critical habitat needs within the CRB. In particular, our objectives are to: 1) determine diagnostic characteristics for species identification of embryo and larval stage Pacific, western brook, and river lampreys, and 2) examine the effects of temperature on survival and development of early life stages of these three species. This work will answer questions about lampreys posed by regional fishery managers. Specifically, providing tools for population assessment and the quantification of 
habitat needs will help managers in developing strategies to ensure the long-term stability of lamprey populations. Accurate identification techniques will allow managers to conduct larval lamprey surveys and thus determine the relative abundance of each species in various habitats. Knowledge of early life history characteristics and ecological requirements of these species will aid in future research and management of lampreys in the CRB.

This document presents preliminary analyses of data collected in 2000, 2001, 2002, and 2003 for the purpose of validating current diagnostic characteristics of larval lampreys, and preliminary analyses of data collected in 2001 and 2002 for the purpose of providing morphometric descriptions of embryonic and early larval stage lampreys and for defining their thermal requirements. Information for river lampreys is not included in these analyses due to our inability to locate live specimens within the CRB during the timeline in which we were conducting experiments; however, information that we have gathered regarding this species is presented (River lampreys in the Columbia River Basin; pages 23-29).

\section{Methods}

\section{Laboratory environment}

Unless otherwise noted, animals were held under the following conditions at the U.S. Geological Survey - Columbia River Research Laboratory (CRRL). Water for all research was supplied from the Little White Salmon River, Skamania County, WA. Water was treated using sand filters and temperature was controlled to mimic seasonal thermal trends within the CRB. Temperatures followed ambient Columbia River water temperatures $\left( \pm 0.5^{\circ} \mathrm{C}\right)$ at Bonneville Dam (University of Washington 2003) with the exception that they never exceeded $15^{\circ} \mathrm{C}\left( \pm 0.5^{\circ}\right.$ C). All tanks and aquaria were supplied with flow through water (larvae, sub-adult, and adult western brook lampreys at $0.3 \mathrm{~L} / \mathrm{min}$; sub-adult and adult Pacific lampreys at $0.3 \mathrm{~L} \cdot \mathrm{min}^{-1} \cdot \mathrm{kg}^{-1}$ ), a 
source of aeration, suitable burrowing substrate (larvae, sub-adult, and adult western brook lampreys), and were exposed to a simulated natural photoperiod provided by $25 \mathrm{~W}$ incandescent lights on timers with $0.5 \mathrm{~h}$ of increasing and decreasing illumination at the beginning and ending of each light phase.

\section{Pigmentation based identification of larval lampreys}

In the fall of 1999, larval lampreys were collected from five locations in the CRB: Red River (Clearwater River sub-basin), Entiat River (Snake River sub-basin), John Day River (John Day River sub-basin), Walla Walla River (Walla Walla River sub-basin), and Cedar Creek (Lewis River sub-basin). Ten to 25 larvae from each location were collected by cooperators and transported to the CRRL. Lampreys were divided among four $19 \mathrm{~L}$ aquaria such that individuals were separated based on collection location; 1) Red River, 2) Entiat River, 3) John Day/Walla Walla Rivers, and 4) Cedar Creek. Lampreys were fed a suspension of active yeast and commercial fry feed two or three times per week.

In February 2000, each larva was anesthetized using 250 mg/L MS-222 (tricaine methane sulfonate) buffered with an equal concentration of sodium bicarbonate, measured for total length $(\mathrm{mm})$ and wet mass (g), and identified to the species level based on existing diagnostic characteristics (Richards et al. 1982). Approximately $50 \%$ of the larvae from each species by collection location were terminally sampled (overdose of buffered MS-222; $750 \mathrm{mg} / \mathrm{L}$ ) to provide tissue for genetic testing (Appendix 1). Mitochondrial DNA was examined in an effort to genetically confirm species identification (conducted by Dr. Matt Powell, University of Idaho). Thirty-one larvae were uniquely marked with an injection of dyed elastomer, held at the CRRL, and sampled at intervals of approximately six-weeks (Appendix 2). At each sampling event, lampreys were removed from aquaria, anesthetized using buffered MS-222 (250 mg/L), 
measured for length and mass, identified to the species level (Richards et al. 1982), and digital images of their caudal region were taken (Figure 1). Digital images were captured using a Spot Insight digital camera (Diagnostic Instruments, Inc., Sterling Heights, MI) mounted to a stereomicroscope (Wild M3Z, Leica AG, Heerbrugg, Switzerland). This procedure was performed to determine 1) if it is possible to separate these species based on pigmentation patterns (Richards et al. 1982), and 2) if there is a change in pigmentation patterns over time, specifically with regards to diagnostic characteristics of these species. This process was repeated until individuals metamorphosed, at which point species identification could be confirmed based on dentition (Vladykov and Follett 1965; Eddy and Underhill 1978), or individuals died, at which point genetic samples were collected for analysis.

\section{Brood stock collection and holding conditions}

Lamprey embryos and larvae used in this project were the result of lampreys artificially spawned in the laboratory. Brood stock sample sizes and animal size measurements are summarized in Table 1. In the springs of 2001 and 2002, sub-adult Pacific lampreys were collected from the Columbia River at the Bonneville Dam north shore fish ladder (Skamania County, WA), and sub-adult western brook lampreys were collected from Gibbons Creek (Clark County, WA) and Yellowhawk Creek (Walla Walla County, WA). Both species were transported to the CRRL and held until sexually mature. At the CRRL, Pacific lampreys were held in $1400 \mathrm{~L}$ circular tanks and western brook lampreys were held in $38 \mathrm{~L}$ aquaria. Once lampreys reached sexual maturity, individuals were anesthetized using buffered MS-222 (250 $\mathrm{mg} / \mathrm{L}$ ) and rinsed in fresh water to remove traces of anesthetic. Female lampreys were positioned over a glass bowl filled with approximately $2 \mathrm{~L}$ of fresh water at the same temperature as the holding tanks and aquaria. Eggs were forced out the urogenital opening by squeezing the 
abdomen in a downward motion. This was repeated until blood appeared with the gametes. Sperm was removed from males in a similar fashion. Gametes were mixed with a gentle flow of water from a large pipette for $5 \mathrm{~min}$ and allowed to rest undisturbed for $30 \mathrm{~min}$ to allow fertilization to occur.

\section{Morphometric identification of early life stage lampreys}

The following procedures were performed in 2001 and 2002 on both Pacific and western brook lampreys. Following artificial spawning (see above) the temperature of the fertilized eggs was adjusted through the addition of cool water until the target temperature of $14^{\circ} \mathrm{C}$ was reached (approximately $30 \mathrm{~min}$ ), and the fertilized eggs were transferred to flow-through hatching jars (6.86 L McDonald type). Hatching jars were provided with a continuous inflow (approximately 1.5 L/min) of aerated, filtered (sand filter), and sterilized (ultraviolet sterilizer) river water maintained at a temperature of $14^{\circ} \mathrm{C}$. Individuals were held in hatching jars from fertilization until animals had hatched and reached stage 17 (burrowing; Piavis 1961), at which point lampreys were transferred to $19 \mathrm{~L}$ aquaria. Larvae were fed a suspension of active yeast and commercial fry feed three times per week. Hatching jar temperature control was lost for a portion of the incubation period in 2001 due to equipment failure, during which time temperature decreased to approximately $10^{\circ} \mathrm{C}$. Temperatures remained at approximately $10^{\circ} \mathrm{C}$ from 17 days post-fertilization for Pacific lampreys and 12 days post-fertilization for western brook lampreys until lampreys were transferred to aquaria.

Lampreys were sampled periodically to provide morphometric and meristic information. Embryos were sampled daily from the time of fertilization until just prior to hatching (approximately 15 days; Figure 2). Larvae were sampled from the time that they reached stage 17 and at various times during the first year of their larval life stage (stage 18; Piavis 1961; 
Figure 3). At each sampling event, ten individuals were removed from their holding vessel (flow-through hatching jar or aquaria), anesthetized with buffered MS-222 (250 mg/L), digitized, and preserved in 10\% formalin (formaldehyde solution). Digital images were captured using a Spot Insight digital camera (Diagnostic Instruments, Inc., Sterling Heights, MI) mounted to a stereomicroscope (Wild M3Z, Leica AG, Heerbrugg, Switzerland). Image analysis software (Image Pro Plus, Media Cybernetics, Silver Spring, MD) was used to measure digitized specimens. For embryos, measurements consisted of the mean chorion diameter (Figure 4), which was determined by tracing the chorion circumference and making 180 diameter measurements through the embryo's centroid at 2-degree intervals. For larvae, a set of eight homologous landmarks were established (Figure 5a; Appendix 3) and their coordinates where quantified. The locations of the landmarks defined a two-cell truss network with two appended triangles (Bookstein et al. 1985) for which the truss element lengths were calculated (Figure 5b; Appendix 3). Length measurements (i.e., truss element lengths and standard length) were log transformed (base $e$ ) to stabilize variance caused by variability in size (Jolicoeur 1963; Humphries et al. 1981), and used for morphometric descriptions of larval lampreys.

All analyses were performed using SAS software (SAS version 8.1, SAS Institute Inc., Cary, NC) with statistical significance set at $\alpha=0.05$ unless noted otherwise. For embryos, the difference in mean chorion diameter between species was analyzed using an unpaired $t$-test. Due to unequal variance, an approximate $t$-statistic was calculated using estimated degrees of freedom based on the Satterthwaite approximation (Satterthwaite 1946). For larvae, principle components analysis was used to examine the relationship among the log transformed length measurements. Discriminant analysis was performed on the log transformed length measurements. Both full model and reduced model discriminant analyses were examined for 
their ability to accurately predict group membership. The reduced model was produced by a stepwise, backward elimination procedure with the probability to stay in the model set at $\alpha=$ 0.15. For each analysis a classification dataset composed of a random sample of $90 \%$ of the individuals was used to produce classification functions (Tabachnick and Fidell 1996). A test dataset composed of the remaining lampreys was used to test the classification functions.

\section{Effects of temperature on early life stage lampreys}

The following procedures were performed in 2001 and 2002 on both Pacific and western brook lampreys. Following artificial spawning (see above) fertilized eggs were divided into four glass bowls and the temperature of the water in each bowl was gradually adjusted through the addition of cool or warm water until the target temperatures of $10^{\circ} \mathrm{C}, 14^{\circ} \mathrm{C}, 18^{\circ} \mathrm{C}$, and $22^{\circ} \mathrm{C}$ were reached (approximately $30 \mathrm{~min}$ ). Once target temperatures were reached, fertilized eggs were transferred to flow-through hatching jars (6.86 L McDonald type) of the appropriate temperature (one hatching jar per temperature).

Following fertilization, zygotes were incubated at $10^{\circ} \mathrm{C}, 14^{\circ} \mathrm{C}, 18^{\circ} \mathrm{C}$, and $22^{\circ} \mathrm{C}$ for 15 temperature units (degrees above $0^{\circ} \mathrm{C} \cdot$ days), after which 100 viable embryos were placed into each of 10 rearing vessels per temperature. A lag of 15 temperature units between the time of fertilization and the time of selecting experimental individuals was used to allow development to reach a point where fertilization could be confirmed. Each rearing vessel had a volume of approximately $60 \mathrm{ml}$ and was constructed with a screen bottom to allow water to flow through. Rearing vessels were placed into a water bath of the appropriate rearing temperature $\left(10^{\circ} \mathrm{C}, 14^{\circ}\right.$ $\mathrm{C}, 18^{\circ} \mathrm{C}$, and $22^{\circ} \mathrm{C}$ ), and each vessel was supplied with freshwater inflow at a rate of 0.05 $\mathrm{L} / \mathrm{min}$. Water supplied to rearing vessels and illumination was similar to above (i.e., Laboratory environment) with the addition of water treatment by ultraviolet sterilizers. Water supplied to 
rearing vessels was monitored daily for dissolved oxygen concentration, $\mathrm{pH}$, and total dissolved gasses (Figure 6, 7,8).

Individuals in each rearing vessel were examined daily for the duration of the experiment, which lasted from the time that individuals were assigned to a rearing vessel until individuals had reached the larval stage (i.e., stage 18; Piavis 1961; Figure 3). The larval stage is marked by differentiation of all systems (except genital) and the extrusion of yolk from the gut (Piavis 1961). For daily examinations, each rearing vessel was removed from the incubation bath, placed in a petri dish with water of the appropriate temperature, and examined under a stereomicroscope at 10X to 40X (Wild M3Z, Leica AG, Heerbrugg, Switzerland). The number of individuals hatched/not hatched, the number of surviving individuals, and the number of abnormal larvae were recorded. Dead individuals were removed from rearing vessels daily. Larval abnormalities were traits considered to have a potential negative effect on survival or fitness in conditions less favorable than a laboratory setting, such as malformations of the body (Piavis 1961). For examples of normal and abnormal larvae see Figure 9 and Figure 10.

All statistical analyses were performed at $\alpha=0.05$ using SAS software (SAS version 8.01, SAS Institute Inc., Cary, NC). Less than 20 replicates ( 10 replicates $\cdot 2$ years) were available for some treatment combinations due to mechanical trauma resulting from improperly adjusted freshwater inflow. Due to unbalanced data, degrees of freedom were estimated following Satterthwaite (1946). Using the number of individuals hatched/not hatched for each rearing vessel, logistic regression was used to estimate the number of days to $50 \%$ hatch $\left(D_{\mathrm{H} 50}\right)$ and the number of days to $95 \%$ hatch $\left(D_{\mathrm{H} 95}\right)$ (terminology follows Rodríguez-Muñoz et al. 2001). For each species, a linear regression model was fit to describe the effects of temperature on the development rate to $50 \%$ hatch. We then estimated the temperature for zero development 
$\left(T_{0}\right)$, the effective temperature $\left(E_{\mathrm{T}}=T-T_{0}\right)$, and the accumulated degree-days to which individuals were exposed ( $D D=E_{\mathrm{T}} \cdot$ Days). Degree-days were calculated in order to provide a standardized measure for the effects of time and temperature on development. The number of days individuals were held under experimental conditions (see above) was the days required to reach the larval stage $\left(D_{\mathrm{L}}\right)$. A repeated measures factorial analysis of variance was used to examine the effects of species and rearing temperature on the proportion of individuals surviving to hatch $\left(S_{\mathrm{H}}=\right.$ proportion of individuals surviving to $\left.D_{\mathrm{H} 95}\right)$ and the proportion of individuals surviving to the larval stage $\left(S_{\mathrm{L}}=\right.$ proportion of individuals surviving to $\left.D_{\mathrm{L}}\right)$. A factorial analysis of variance was used to examine the effects of species and rearing temperature on the proportion of abnormal individuals at the larval stage $\left(A_{\mathrm{L}}=\right.$ proportion of abnormal larvae at $\left.D_{\mathrm{L}}\right)$. Year (2001 and 2002) was included as a blocking factor in all analyses to account for systematic variation associated with the time the experiment was performed (Sokal and Rohlf 1995). Variance in response variables was stabilized using an arcsin transformation for $S_{\mathrm{H}}$ and $S_{\mathrm{L}}$, and a square-root transformation for $A_{\mathrm{L}}$. When main factors had an overall significant effect, Bonferroni $t$-tests were used to make pairwise comparisons between treatment combinations. Statistical comparisons are based on transformed data; however, reported mean values are based on the original measurement scale (Kuehl 1994).

\section{Preliminary results and discussion}

\section{Pigmentation based identification of larval lampreys}

In February 2000, 50 larval lampreys were sacrificed to provide genetic material for mitochondrial DNA analysis. Of these individuals, 42 were identified as Pacific lampreys and eight were identified as western brook lampreys based on caudal region pigmentation (Richards et al. 1982; Appendix 1). Researchers at the University of Idaho were unable to locate genetic 
sequences or loci suitable for differentiating Pacific and western brook lampreys. This inability to separate CRB lampreys may be a result of the molecular techniques used. Docker et al. (1999) were able to separate Pacific lampreys from the composite group of western brook and river lampreys; however, they were unable to genetically distinguish western brook and river lampreys from each other. Based on these data, Docker et al. (1999) suggests western brook and river lampreys diverged within the past 70,000 years. Due to this recent divergence, mitochondrial DNA may not be suitable for separation of lamprey species found in the CRB; therefore, other techniques, such as microsatellite analysis, may merit investigation. The ability to accurately identify $\mathrm{CRB}$ lampreys is essential to productive management actions; therefore, samples provided to the University of Idaho are being returned so that we may archive them for later analysis and development of suitable molecular techniques for differentiating lampreys found in the CRB.

The 31 larvae held at the CRRL for repeated examination were sampled up to 30 times (some individuals less due to mortality) (Appendix 2). In the case of mortality, genetic samples were taken for later species confirmation. Of these larvae, species identification was confirmed, based on dentition patterns (Vladykov and Follett 1965; Eddy and Underhill 1978), for two Pacific lampreys that metamorphosed. These individuals were consistently identified as Pacific lampreys (100\% of the sampling events). Species identification was also consistent for 28 of the un-metamorphosed lampreys. Only one individual was identified inconsistently (Pacific lamprey in $83 \%$ of the sampling events; western brook lamprey in $17 \%$ of the sampling events). Preliminary results indicate that over time there is not a significant change in pigmentation patterns associated with species identification. 


\section{Morphometric identification of early life stage lampreys}

Mean chorion diameter was greater and more variable for Pacific lampreys $(1.468 \pm$ $0.107 \mathrm{~mm}, N=320)$ than for western brook lampreys $(1.237 \pm 0.064 \mathrm{~mm}, N=280)$. An unpaired $t$-test showed that the difference in mean chorion diameter between species was highly significant $(t=32.788, \mathrm{df}=528.62, P<0.0001)$ with a mean difference of $0.231 \mathrm{~mm}$. Although a highly significant difference was observed, the magnitude of the difference was at a scale that would be difficult to measure under field conditions. Chorion diameter was chosen as a potential measurement for distinguishing between lamprey species because it remains relatively constant throughout development from fertilization to hatching. Also, because of the chorion's spherical shape, diameter measurements should be roughly equivalent regardless of egg orientation. Other measurements related to the size and shape of developing embryos may be useful for species identification; however, the dynamic nature and 3-dimentional complexity of developing embryos (Figure 2) would make this a daunting task even under the most controlled conditions.

For early life stage larvae, the first two principal components accounted for $97 \%$ of the variability in the length measurements, with $93 \%$ of the variability accounted for by PC1. Positive loadings on PC1 were observed for all variables (Table 2; Figure 11) indicating a positive relationship among all measured dimensions and suggesting PC1 may be a good descriptor of the general size of the animals examined (Bookstein et al. 1985; Bookstein 1991). While relatively similar in magnitude, slight differences in loadings indicate allometric growth (Bookstein et al. 1985). For PC2, truss elements defining body regions grouped together well and suggest differential rates of growth associated with body region or changes in animal shape associated with general size over the size range of lampreys examined. Large negative loadings were observed for truss elements A, B, C, E, and G, associated with the preorbital and branchial 
regions, and large positive loadings were observed for truss elements I, J, K, L, and M, associated with the trunk region (Table 2; Figure 11).

The full model discriminant analysis correctly classified $92 \%$ of the Pacific lampreys and $93 \%$ of the western brook lampreys in the classification data set (see Table 3 for parameter estimates for the classification functions). When applied to the test data set, the classification functions correctly classified $91 \%$ of the Pacific lampreys and $85 \%$ of the western brook lampreys. The backward elimination procedure removed the variables standard length, truss element A, truss element I, and truss element $\mathrm{K}$ from the model. The reduced model correctly classified $91 \%$ of the Pacific lampreys and $93 \%$ of the western brook lampreys in the classification data set. When applied to the test data set, the classification functions correctly classified $91 \%$ of the Pacific lampreys and $85 \%$ of the western brook lampreys.

We found that a high percentage of Pacific and western brook lampreys could be classified using landmark based morphometrics. This technique may have practical applications when species identity must be determined for individuals that have not yet fully developed characteristic pigment patterns. However, the scale at which measurements must be taken will require specialized equipment and training and may not be applicable to field situations.

\section{Effects of temperature on early life stage lampreys}

Mean $D_{\mathrm{H} 50}$ and $D_{\mathrm{H} 95}$ (Table 4 ) varied greatly among temperatures, and temperature accounted for a large proportion of the observed variance in developmental rate $\left(1 / D_{\mathrm{H} 50}\right)$ for Pacific $\left(r^{2}=0.9864\right)$ and western brook $\left(r^{2}=0.9828\right)$ lampreys. $T_{0}$ estimates from linear regression models were $4.85^{\circ} \mathrm{C}$ for Pacific and $4.97^{\circ} \mathrm{C}$ for western brook lampreys, and were used to calculate effective temperatures (Table 4). 
Prior to examining the effects of temperature and species on $S_{\mathrm{H}}$ and $S_{\mathrm{L}}$, interactions among species, temperature, and development stage (hatch and larva) were examined. There was not a significant interaction between species and temperature $\left(F_{3,116}=1.20, P=0.31\right)$, species and development stage $\left(F_{1,120}=1.90, P=0.17\right)$, or temperature and development stage $\left(F_{3,120}=1.56, P=0.20\right)$; therefore, data were combined to examine the effects of main factors on survival. There was a significant difference in survival among temperatures $\left(F_{3,116}=198.47, P<\right.$ $0.0001)$ and species $\left(F_{1,116}=5.22, P=0.02\right)$, and there was a significant difference in survival at hatching and at the larval stage $\left(F_{1,120}=53.77, P<0.0001\right)$. Survival was greatest at $18^{\circ} \mathrm{C}$ followed by $14^{\circ} \mathrm{C}, 10^{\circ} \mathrm{C}$, and $22^{\circ} \mathrm{C}$ (Figure 12), and mean comparisons indicated that survival was significantly reduced at $22^{\circ} \mathrm{C}$ when compared to $10^{\circ} \mathrm{C}(t=19.38, \mathrm{df}=116, P<0.0001)$, $14^{\circ} \mathrm{C}(t=15.82, \mathrm{df}=116, P<0.0001)$, or $18^{\circ} \mathrm{C}(t=21.40, \mathrm{df}=116, P<0.0001)$. Significant differences were not observed between other temperatures $(P>0.05)$.

Survival was significantly greater for western brook lampreys than for Pacific lampreys ( $t$ $=-2.28, \mathrm{df}=116, P=0.02)$; however, this difference may be due to the small degree of variability in the transformed data, as the difference in the proportion of individuals surviving between the species was only 0.02 . Similarly, a significant decrease in survival occurred after hatch $(t=7.33, \mathrm{df}=120, P<0.0001)$, although the difference between $S_{\mathrm{H}}$ and $S_{\mathrm{L}}$ was only 0.03 (Figure 13).

There was not a significant interaction between species and temperature on the proportion of individuals exhibiting abnormalities at the larval stage $\left(F_{3,111}=2.33, P=0.08\right)$. There was a significant difference in the occurrence of abnormalities among temperatures $\left(F_{3,111}=127.49, P\right.$ $<0.0001)$, but not among species $\left(F_{1,111}=0.33, P=0.56\right)$. The occurrence of abnormalities was greatest at $22^{\circ} \mathrm{C}$ followed by $18^{\circ} \mathrm{C}, 10^{\circ} \mathrm{C}$, and $14^{\circ} \mathrm{C}$ (Figure 14). Significant differences in the 
occurrence of abnormalities were observed between $22^{\circ} \mathrm{C}$ and $18^{\circ} \mathrm{C}(t=-16.36, \mathrm{df}=111, P<$ $0.0001), 14^{\circ} \mathrm{C}(t=-13.61, \mathrm{df}=111, P<0.0001)$, and $10^{\circ} \mathrm{C}(t=-15.38, \mathrm{df}=111, P<0.0001)$; however, significant differences were not observed between other temperatures $(P>0.05)$.

Overall, Pacific and western brook lampreys responded similarly to temperature. Estimated days to $50 \%$ and $95 \%$ hatch were very consistent among species (Table 4 ), as were the predicted temperatures for zero development. Although a systematic difference was observed in the overall proportion of individuals surviving between the two species, the biological significance associated with the small magnitude of the difference is questionable. The slight increase in survival from $10^{\circ} \mathrm{C}$ to $18^{\circ} \mathrm{C}$ followed by a sharp decline in survival at $22^{\circ} \mathrm{C}$ suggests that over the range of temperatures examined, survival was optimum in the range of $10^{\circ}$ $\mathrm{C}$ to $18^{\circ} \mathrm{C}$. This is supported by the low occurrence of abnormalities at $10^{\circ} \mathrm{C}, 14^{\circ} \mathrm{C}$, and $18^{\circ} \mathrm{C}$, and the significant increase in abnormalities at $22^{\circ} \mathrm{C}$.

The similarity in response to temperature by Pacific and western brook lampreys in this experiment suggests similar reproductive timing and thermal habitat requirements for early life stage development. Under conditions of sympatric distributions this may result in interspecific competition and partitioning of thermal resources for spawning and rearing habitats (Magnuson et al. 1979). While anecdotal data are abundant, quantitative distribution data for Pacific lampreys within the Columbia River Basin are limited to fish passage data collected at hydroelectric projects along the mainstem Columbia and Snake Rivers and a small number of localized studies (e.g., Cochnauer and Claire 2001; Close 2002). Distribution data for western brook lampreys within the CRB are essentially nonexistent. Therefore, the degree to which these species exhibit a sympatric distribution is unknown; however, both species have been observed 
concurrently within the same Columbia River tributary (Gibbons Creek, WA; personal observation).

The relationship between temperature and reproductive timing may also have an affect on growth and long-term survival of fish. In general, the thermal tolerance zone for embryological development of fish is believed to be narrow; however, there is less agreement on the temperature sensitivity of other life stages and fish sizes (Brett 1970; Elliott 1981; Rombough 1988). For example, the most stenothermic life stage for sea lampreys appears to be the embryo, with a broader and more variable range of thermal tolerance for larvae, juveniles, and adults (see Rodríguez-Muñoz et al. 2001). Therefore, spawning generally occurs within a specific range of temperatures suitable for embryological development (Brett 1970), and often occurs under thermal conditions that maximize survival, energy conversion (Blaxter 1969), and individual size at specific developmental stages (Atkinson 1994). However, thermal conditions that are optimal for embryological development may result in hatching when thermal conditions are sub-optimal for later life stages (Brett 1970).

In this experiment, examining the effects of temperature on survival to hatch and survival to the larval stage essentially allowed us to examine potential changes in the effects of temperature on survival for pre and post hatch individuals. Overall, there was a significant decrease in survival from the time of hatch $(155.6 \pm 10.8 \mathrm{DD})$ to the time that individuals reached the larval stage $(294.0 \pm 10.2 \mathrm{DD})$ indicating that mortality continued after hatch. However, a change in the trend of individuals surviving over time is apparent when survival is plotted against degree-days (Figure 13). From fertilization to hatch the overall proportion of individuals surviving decreased from 1.00 to 0.85 , whereas the proportion of individuals surviving from hatch to the larval stage only decreased from 0.85 to 0.82 . Because lampreys 
exposed to $10^{\circ} \mathrm{C}, 14^{\circ} \mathrm{C}$, and $18^{\circ} \mathrm{C}$ exhibited high survival rates throughout the duration of the experiment, individuals exposed to $22^{\circ} \mathrm{C}$ likely had the greatest influence on the observed trend (Figure 12). Nevertheless, interactions were not observed among the factors examined; therefore, changes in survival rates were statistically systematic among temperatures. These data suggest a shift in the effect of temperature on survival based on ontogenetic stage, which may allow survival of post-hatch individuals over a broad range of environmental conditions.

\section{River lampreys in the Columbia River Basin}

The main objectives of this study were to examine questions regarding the biology of three species of lampreys found in the CRB. While both Pacific lampreys and western brook lampreys were conveniently found in the mainstem or tributaries to the Columbia River, river lampreys have proven more elusive. River lampreys are an anadromous species historically found in the CRB, and have been collected in the CRB as recently as 1980 (Bond et al. 1983). For this project, we were unable to locate river lampreys in the CRB. Their absence from catch records suggests that they are scarce in this area or may be locally extinct. In 1999, we started to search for river lampreys and have since discovered a need for basic information on the biology of this species.

The river lamprey is an understudied species; much of the information that we have comes from studying other predatory lamprey species. We do know that post-metamorphic river lampreys can be distinguished from other predatory lamprey species using dentition and coloration patterns. The dentition consists of two large teeth on the supraoral lamina, a large middle tooth on the transverse lingual lamina, and 3 points (rarely 2) on each central lateral tooth plate (Eddy and Underhill 1978). Coloration patterns consist of a counter shaded silver body, with a slightly green tint on the upper and mid sections of the body. We also observed a dark 
black-pigmented line along the base of both dorsal fins and a patch of pigmentation in the caudal fin. It is believed that river lampreys metamorphose in late July, with downstream migration occurring the following year from late April to July (Beamish 1980b). During the predatory phase, river lampreys attach to their prey, rasp through the outer layers of skin and scales, and feed on the host's body fluids. In laboratory studies they have been observed to feed on small salmonids (Family: Salmonidae), Pacific herring (Clupea pallasii), shiner perch (Cymatogaster aggregata), and English sole (Parophrys vetulus) (Beamish 1980b). The final phase of the life cycle, the spawning phase, begins once feeding ceases; occurring from late fall to May of the following year (Beamish 1980b). During this time, river lampreys will start their upstream migration into the fresh-water system to spawn.

Collection records indicate that river lampreys historically inhabited coastal stream systems from Taku River, AK, south to the San Francisco Bay, CA (Hart 1980). All of the specimens for which records are available are predatory phase individuals that were collected as incidental catch from estuaries and bays along the northwest Pacific coast. Documentation of larval river lampreys has proven extremely difficult and uncommon, which has been attributed to the difficulty in distinguishing among larval lampreys. Analyses of mitochondrial DNA from northern hemisphere lampreys has helped to distinguish between 11 species within the Lampetra genus. This method used a 735 base pair sequence from the cytochrome $b$ and NADH dehydrogenase subunit 3 (ND3) to aid in differentiating between species. Presently, this form of genetic testing indicates a distinct difference between Pacific lampreys when compared to western brook and river lampreys. However, river and western brook lampreys are considered satellite species and genetically inseparable using this method of testing. This would suggest a divergence time of less than 70,000 years ago (Docker et al. 1999). The lack of general 
knowledge and inability to distinguish between the three CRB species in the field has led to misidentification and inaccurate reporting, which complicated our search.

In the fall of 1999, we started looking for river lampreys and originally restricted our search to the CRB. By 2001 we realized that a more extensive search area was required, so we expanded it to include coastal rivers and estuaries from California to Canada (for an overview of agencies and organizations contacted see Appendix 4). Within the CRB, we spoke with personnel from universities and state, federal, tribal, and private agencies in an attempt to collect river lampreys. Initially, the Oregon Department of Fish and Wildlife (ODFW) and Washington Department of Fish and Wildlife (WDFW) were contacted to establish a list of possible collection locations. Individuals contacted within these agencies stated that there have been no sightings of adult river lampreys and that they have no way of distinguishing between the three CRB species during larval life stages. Individuals contacted at both the Fish Passage Center for the Columbia River and the Lower Columbia River Estuary Program reported no sightings. According to the National Oceanic and Atmospheric Administration Fisheries (NOAA Fisheries), most of their recent sampling had been conducted in the Columbia River estuary where they were performing bottom and mid-water column trawls that were not conducive to lamprey collection. The Yakama Nation reported that they had no sightings of river lampreys on the Klickitat River. Both Oregon State University and the University of Washington currently have specimens of predatory phase river lampreys collected in the CRB, but none collected after 1980. The University of Washington has river lamprey specimens that were collected as recently as 2000 from Lake Washington, WA (outside the CRB). Also contacted were the Point No Point Treaty Council and the Lower Elwha Klallam Tribe from the Puget Sound region of Washington. The Lower Elwha Klallam Tribe was the most promising, with records indicating capture of 
river lampreys in the past, but nothing currently. In Oregon, the Confederated Tribes of the Siletz Indian Reservation reported collecting river lampreys in the past, but has not had any recent sightings. Local WDFW and ODFW offices were contacted for Puget Sound, the Klickitat River Basin, the Willamette River Basin, the Umpqua River Basin, and the Smith River Basin. None of these offices recorded sightings or collections of river lampreys. The Hatfield Marine Science Center in Newport, OR, was unable to provide us with new information on search locations. In California, we contacted both the Steinhart Aquarium and the Monterey Bay Aquarium, neither of which have live lampreys on site. The Steinhart Aquarium has preserved specimens of river lampreys in their ichthyology collection, the most recent of which was collected in Marin County, CA, in 1971. In Canada, river lampreys have been collected for research purposes within the Strait of Georgia and in the Fraser River Basin; however, few have been collected in recent years and their population status is unknown. Because of this, researchers and managers were hesitant to supply us with any river lampreys until more accurate population data are available.

In June 2002, 54 river lampreys were located and captured by NOAA Fisheries in northern Skagit Bay, WA. Specimens were captured as incidental catch during surface trawls using a tow net ( $6 \mathrm{~m}$ wide by $3 \mathrm{~m}$ deep) with mesh sizes ranging from $8.9 \mathrm{~cm}$ at the front to 0.6 $\mathrm{cm}$ at the codend. NOAA Fisheries catch records indicated that river lampreys were present in the surface waters of Skagit Bay, WA, from April until October, peaking from June to August (Table 5). These predatory phase river lampreys were identified using dentition and color patterns.

The river lampreys collected were sexually immature and therefore could not be used for this project. However, due to the difficulty we encountered in locating and collecting live river 
lampreys, we explored the feasibility of maintaining river lampreys in a laboratory setting through the time of sexual maturation. River lampreys were transported to the CRRL and held for $32 \mathrm{~d}$ in a flow through, $189 \mathrm{~L}$ aquarium (see above; Laboratory environment) until a suitable seawater capable facility could be found. During this period, they were provided a diet of Chinook salmon (Oncorhynchus tshawytscha) smolts, but they only fed sporadically and some mortality occurred. On July 9, 2002, the remaining 36 river lampreys were transferred to USGS Marrowstone Marine Field Station, Nordland, WA. River lampreys were held for 195 d in a 530 $\mathrm{L}$ tank provided with $3.8 \mathrm{~L} / \mathrm{min}$ to $5.7 \mathrm{~L} / \mathrm{min}$ of filtered seawater. Water was pumped from the Puget Sound at a depth of $15 \mathrm{~m}$, sand filtered to $40 \mu \mathrm{m}$, and sterilized using UV sterilizers. Temperature and salinity fluctuated with that of ambient Puget Sound water.

Measurements were taken periodically over the $318 \mathrm{~d}$ that we held the river lampreys in captivity. A mean length of $139 \mathrm{~mm}(\mathrm{SE}=0.55)($ Figure 15) and mean mass of $2.89 \mathrm{~g}(\mathrm{SE}=$ 0.14) (Figure 16) was recorded in early July. Once the river lampreys were returned to a seawater environment, they resumed feeding on a diet of Pacific herring. The river lampreys were voracious feeders, in many cases tearing sections of flesh from the herring and feeding on recently deceased fish. Lampreys ceased feeding in early December, even though herring were still present in the tank. Herring were offered until January when, due to increased mortality, the river lampreys were transferred back to the CRRL and held for $91 \mathrm{~d}$ until the time of spawning. Although sample sizes varied over time due to mortality, mean growth rates where calculated to examine general trends. At the time of transfer, the nine remaining river lampreys had a mean length of $241.33 \mathrm{~mm}(\mathrm{SE}=1.25)$ (Figure 15) and mean mass of $22.63 \mathrm{~g}(\mathrm{SE}=0.63)$ (Figure 16). This suggests a growth rate of $0.52 \mathrm{~mm} / \mathrm{d}$, for the $195 \mathrm{~d}$ that the river lampreys were held in seawater. Once feeding ceased the river lampreys went into a period of negative growth. During 
this time, the mean length of the river lampreys decreased to $198.0 \mathrm{~mm}(\mathrm{SE}=1.74)($ Figure 15) and mean mass of $15.02 \mathrm{~g}(\mathrm{SE}=0.63)$ (Figure 16), which indicates a growth rate of $-0.48 \mathrm{~mm} / \mathrm{d}$ over the remaining $91 \mathrm{~d}$ that the river lampreys were held. In April of 2003, the nine remaining river lampreys started to exhibit secondary sexual characteristics such as swelling on the leading edge of the second dorsal fin, development of an anal fin fold behind the cloaca, an oedematous region developed in front of the cloaca, and visible papilla in males (Hardisty and Potter, 1971b). In late April, four river lampreys were artificially spawned and the embryos were incubated in hatching jars (6.86 L McDonald type) until hatch. At that time, they were transferred into an aquarium with suitable substrate and continue to be held at the CRRL (see above; Laboratory environment).

Initially we had projected spawning of the river lampreys to occur in the spring of 2001 and 2002 along with Pacific lampreys and western brook lampreys. Although river lampreys were located in the spring of 2002, they were not sexually mature and therefore could not be included in our experiments. The river lampreys that were held through sexual maturity and artificially spawned produced viable offspring, which indicates that we will be able to successfully spawn river lampreys in the future. While searching for river lampreys, vast gaps in the basic knowledge of this species emerged. Future studies should be conducted on basic biology as virtually nothing is know of the river lamprey, in particular the larval stage of the life cycle. There are also issues of identification such that if species are not distinguishable, much of the published distribution data may be incorrect. This leads to the question of their historic distribution; are they still present in some of the areas that they were found in the past? There are also questions about habitat, migration, feeding, and basic requirements for survival that need 
to be addressed. Very little is known, which makes studying river lampreys all the more important in order to preserve their place in the ecosystem.

\section{Future goals}

1. Inclusion of meristic data in morphological examination of early larval stage lampreys.

2. Preparation and submission of manuscripts to peer-reviewed scientific journals.

3. Preparation of final report of research to Bonneville Power Administration. 


\section{Literature cited}

Atkinson, D. 1994. Temperature and organism size-a biological law for ectotherms? Advances in Ecological Research 25:1-58.

Beamish, F. W. H. 1980a. Biology of the North American anadromous sea lamprey, Petromyzon marinus. Canadian Journal of Fisheries and Aquatic Sciences 37:1924-1943.

Beamish, R. J. 1980b. Adult biology of the river lamprey (Lampetra ayresi) and the Pacific lamprey (Lampetra tridentata) from the Pacific coast of Canada. Canadian Journal of Fisheries and Aquatic Sciences 37:1906-1923.

Beamish, R. J., and C. D. Levings. 1991. Abundance and freshwater migrations of the anadromous parasitic lamprey, Lampetra tridentata, in a tributary of the Fraser River, British Columbia. Canadian Journal of Fisheries and Aquatic Sciences 48:1250-1263.

Blaxter, J. H. S. 1969. Development: eggs and larvae. Pages 177-252 in W. S. Hoar and D. J. Randall, editors. Fish physiology, volume III. Academic Press, New York, New York.

Bond, C., T. T. Kan, and K. W. Myers. 1983. Notes on the marine life of the river lamprey, Lampetra ayresi, in Yaquina Bay, Oregon, and the Columbia River estuary. Fishery Bulletin 81:165-167.

Bookstein, F. L. 1991. Morphometric tools for landmark data: geometry and biology. Cambridge University Press, New York, New York.

Bookstein, F., B. Chernoff, R. Elder, J. Humphries, G. Smith, and R. Strauss. 1985. Morphometrics in evolutionary biology. The Academy of Natural Sciences of Philadelphia, Special Publication 15, Philadelphia, Pennsylvania.

Brett, J. R. 1970. Temperature. Pages 515-560 in O. Kinne, editor. Marine ecology. WileyInterscience, New York, New York. 
Close, D. A. 2002. Pacific lamprey research and restoration project. Report of Confederated Tribes of the Umatilla Indian Reservation to U.S. Department of Energy, Portland, Oregon.

Close, D. A., M. Fitzpatrick, H. Li, B. Parker, D. Hatch, and G. James. 1995. Status report of the Pacific lamprey (Lampetra tridentata) in the Columbia Basin. Report (Contract 95BI39067) to Bonneville Power Administration, Portland, Oregon.

Cochnauer, T., and C. Claire. 2001. Evaluate status of Pacific lamprey in the Clearwater River drainage, Idaho. Report of Idaho Department of Fish and Game to U.S. Department of Energy, Portland, Oregon.

Docker, M. F., J. H. Youson, R. J. Beamish, and R. H. Devlin. 1999. Phylogeny of the lamprey genus Lampetra inferred from mitocondrial cytochrome $b$ and ND3 gene sequences. Canadian Journal of Fisheries and Aquatic Sciences 56:2340-2349.

Eddy, S., and J. C. Underhill. 1978. How to know the freshwater fishes, $3^{\text {rd }}$ edition. Wm. C. Brown Company Publishers, Dubuque, Iowa.

Elliott, J. M. 1981. Some aspects of thermal stress on freshwater teleosts. Pages 209-245 in A. D. Pickering, editor. Stress and fish. Academic Press, New York, New York. Hammond, R. J. 1979. Larval biology of the Pacific lamprey, Entosphenus tridentatus (Gairdner), of the Potlach River, Idaho. Master's thesis. University of Idaho, Moscow. Hardisty, M. W., and I. C. Potter. 1971a. The behaviour, ecology, and growth of larval lampreys. Pages 85-126 in M. W. Hardisty and I. C. Potter, editors. The biology of lampreys, volume 1. Academic Press, New York, New York. 
Hardisty, M. W., and I. C. Potter. 1971b. The general biology of adult lampreys. Pages 127206 in M. W. Hardisty and I. C. Potter, editors. The biology of lampreys, volume 1. Academic Press, New York, New York.

Hart, J. L. 1973. Pacific Fishes of Canada. Fisheries Research Board of Canada, Ottawa, Canada.

Holmes, J. A., and P. Lin. 1994. Thermal niche of larval sea lamprey, Petromyzon marinus. Canadian Journal of Fisheries and Aquatic Sciences 51:253-262.

Houde, E. D. 1987. Fish early life history dynamics and recruitment variability. American Fisheries Society Symposium 2, pp. 17-29.

Humphries, J. M., F. L. Bookstein, B. Chernoff, G. R. Smith, R. L. Elder, and S. G. Poss. 1981. Multivariate discrimination by shape in relation to size. Systematic Zoology 30:291-308.

Jolicoeur, P. 1963. The multivariate generalization of the allometry equation. Biometrics 19:497-499.

Kan, T. T. 1975. Systematics, variation, distribution, and biology of lampreys of the genus Lampetra in Oregon. Doctoral thesis. Oregon State University, Corvallis.

Kuehl, R. O. 1994. Statistical principles of research design and analysis. Duxbury Press, Belmont, California.

Magnuson, J. J., L. B. Crowder, and P. A. Medvick. 1979. Temperature as an ecological resource. American Zoologist 19:331-343.

McCauley, R. W. 1963. Lethal temperatures of the developmental stages of the Sea Lamprey, Petromyzon marinus L. Journal of the Fisheries Research Board of Canada 20:483-490. Moyle, P. B., and J. J. Cech, Jr. 1996. Fishes: An introduction to ichthyology, $3^{\text {rd }}$ edition. Prentice Hall, Upper Saddle River, New Jersey. 
NPPC (Northwest Power Planning Council). 1994. Columbia Basin Fish and Wildlife Program. Portland, Oregon.

Pletcher, F. T. 1963. The life history and distribution of lampreys in the Salmon and certain other rivers in British Columbia, Canada. Master's thesis. University of British Columbia, Vancouver.

Piavis, G. W. 1961. Embryological stages in the sea lamprey and effects of temperature on development. Fishery Bulletin 61:111-143.

Potter, I. C., and F. W. H. Beamish. 1975. Lethal temperatures in ammocoetes of four species of lampreys. Acta Zoologica 56:85-91.

Quinn, T. P., and D. J. Adams. 1996. Environmental changes affecting the migratory timing of American shad and sockeye salmon. Ecology 77:1151-1162.

Richards, J. E. 1980. The freshwater biology of the anadromous Pacific lamprey (Lampetra tridentata). Master's thesis. University of Guelph, Guelph, Ontario.

Richards, J. E., R. J. Beamish, and F. W. H. Beamish. 1982. Descriptions and keys for ammocoetes of lampreys from British Columbia, Canada. Canadian Journal of Fisheries and Aquatic Sciences 39:1484-1495.

Rodríguez-Muñoz, R., A. G. Nicieza, and F. Braña. 2001. Effects of temperature on developmental performance, survival and growth of sea lamprey embryos. Journal of Fish Biology 58:475-486.

Rombough, P. J. 1988. Respiratory gas exchange, aerobic metabolism, and effects of hypoxia during early life. Pages 59-161 in W. S. Hoar and D. J. Randall, editors. Fish physiology, volume XI. Academic Press, New York, New York. 
Satterthwaite, F. E. 1946. An approximate distribution of estimates of variance components. Biometrics 2:110-114.

Sokal, R. R., and F. J. Rohlf. 1995. Biometry, $3^{\text {rd }}$ edition. Freeman and Company, New York, New York.

Tabachnick, B. G., and L. S. Fidell. 1996. Using multivariate statistics, $4^{\text {th }}$ edition. Allyn and Bacon, Boston, Massachusetts.

University of Washington. 2003. Columbia River DART: Data Access in Real Time. School of Aquatic and Fishery Sciences. Available: www.cbr.washington.edu/dart/dart.html. (November 2003).

Vladykov, V. D., and W. I. Follett. 1965. Lampetra richardsoni, a new nonparasitic species of lamprey (Petromyzonidae) from western North America. Journal of the Fisheries Research Board of Canada 22:139-158.

Young, R. J., J. R. M. Kelso, and J. G. Weise. 1990. Occurrence, relative abundance, and size of landlocked sea lamprey (Petromyzon marinus) ammocoetes in relation to stream characteristics in the Great Lakes. Canadian Journal of Fisheries and Aquatic Sciences $47: 1773-1778$.

Youson, J. H., J. A. Holmes, J. A. Guchardi, J. G. Seelye, R. E. Beaver, J. E. Gersmehl, S. A. Sower, and F. W. H. Beamish. 1993. Importance of condition factor and the influence of water temperature and photoperiod on metamorphosis of sea lamprey, Petromyzon marinus. Canadian Journal of Fisheries and Aquatic Sciences 50:2448-2456. 
Table 1: Sex, sample size, mean total length, and mean wet mass of Pacific and western brook lampreys used to provide gametes for experiments in 2001 and 2002.

\begin{tabular}{|c|c|c|c|c|c|}
\hline Species & Sex & Year & $N$ & Length $(\mathrm{mm} \pm \mathrm{SD})$ & $\operatorname{Mass}(\mathrm{g} \pm \mathrm{SD})$ \\
\hline \multirow[t]{4}{*}{ Pacific lamprey } & Female & 2001 & 5 & $459 \pm 42$ & $318.4 \pm 65.4$ \\
\hline & & 2002 & 6 & $446 \pm 28$ & $292.0 \pm 42.0$ \\
\hline & Male & 2001 & 6 & $508 \pm 41$ & $287.5 \pm 87.9$ \\
\hline & & 2002 & 6 & $480 \pm 37$ & $267.6 \pm 69.5$ \\
\hline \multirow[t]{4}{*}{ Western brook lamprey } & Female & 2001 & 31 & $122 \pm 5$ & $4.236 \pm 0.656$ \\
\hline & & 2002 & 29 & $122 \pm 10$ & $4.545 \pm 1.130$ \\
\hline & Male & 2001 & 19 & $127 \pm 7$ & $3.938 \pm 0.668$ \\
\hline & & 2002 & 28 & $124 \pm 9$ & $3.758 \pm 0.995$ \\
\hline
\end{tabular}


Table 2: Component loadings for principle components I and II associated with larval length measurements (log transformed standard length and truss elements).

\section{Eigenvectors}

\begin{tabular}{ccc} 
Variable & Principle component I & Principle component II \\
\hline LnSL & 0.237276 & 0.169002 \\
LnA & 0.290241 & -0.313597 \\
LnB & 0.255130 & -0.342844 \\
LnC & 0.244516 & -0.207822 \\
LnD & 0.244260 & -0.060370 \\
LnE & 0.277947 & -0.194244 \\
LnF & 0.250561 & -0.096640 \\
LnG & 0.264667 & -0.146598 \\
LnH & 0.189921 & 0.063315 \\
LnI & 0.195816 & 0.368770 \\
LnJ & 0.192611 & 0.354244 \\
LnK & 0.192092 & 0.367000 \\
LnL & 0.195288 & 0.350751 \\
LnM & 0.132638 & 0.334643 \\
LnN & 0.340133 & 0.028515 \\
LnO & 0.380790 & -0.064578 \\
\hline & & \\
\hline & & \\
\hline
\end{tabular}


Table 3: Parameter estimates for classification functions for Pacific (PCL) and western brook (WBL) lamprey larvae derived from discriminant analyses. Classification takes the form: $C_{j}=$ $C_{\mathrm{j} 0}+C_{j 1} X_{1}+C_{j 2} X_{2}+\cdots+C_{j p} X_{p}$, and membership is assigned to the group with the highest classification score (Tabachnick and Fidell, 1996).

\begin{tabular}{ccccc}
\hline & \multicolumn{2}{c}{ Full model } & \multicolumn{2}{c}{ Reduced model } \\
Variable & PCL & WBL & PCL & WBL \\
\hline Constant & -45472 & -45399 & -19897 & -19831 \\
LnSL & 45499 & 45479 &. &. \\
LnA & -2329 & -2330 &. &. \\
LnB & -1447 & -1464 & -94.66590 & -111.31499 \\
LnC & -11476 & -11435 & -12027 & -11987 \\
LnD & -141596 & -141341 & -123293 & -123031 \\
LnE & -139556 & -139286 & 135749 & 135484 \\
LnF & 145082 & 144824 & 135749 & 135484 \\
LnG & 152009 & 151693 & 137643 & 137312 \\
LnH & -12984 & -12951 & -11582 & -11546 \\
LnI & -25867 & -25945 & - &. \\
LnJ & -22596 & -22734 & 484.47835 & 428.43440 \\
LnK & 6478 & 6572 & -390.11622 &. \\
LnL & 14057 & 14201 & -1451 & -1388 \\
LnM & 854.13438 & 814.84661 & 296.33265 & 259.16398 \\
LnN & -2229 & -2200 & -173.94647 & -145.59001 \\
LnO & -4226 & -4241 & .68821 \\
\hline
\end{tabular}


Table 4: Effective temperature $\left(E_{\mathrm{T}}\right)$, days required to reach $50 \%$ hatch $\left(D_{\mathrm{H} 50} \pm \mathrm{SE}\right)$, and days required to reach $95 \%$ hatch $\left(D_{\mathrm{H} 95} \pm \mathrm{SE}\right)$ for Pacific and western brook lampreys reared at four temperatures. $D_{\mathrm{H} 50}$ and $D_{\mathrm{H} 95}$ were estimated independently for each replicate using logistic regression.

\begin{tabular}{lcccc}
\hline & $\begin{array}{r}\text { Temperature } \\
\text { Species }\end{array}$ & $\begin{array}{c}E_{\mathrm{T}} \\
\left({ }^{\circ} \mathrm{C}\right)\end{array}$ & $\begin{array}{c}D_{\mathrm{H} 50} \\
\left({ }^{\circ} \mathrm{C}\right)\end{array}$ & $\begin{array}{c}D_{\mathrm{H} 95} \\
( \pm \mathrm{SE})\end{array}$ \\
\hline Pacific lamprey & 10 & 5.15 & $26.22 \pm 0.57$ & $29.26 \pm 0.50$ \\
& 14 & 9.15 & $16.95 \pm 0.20$ & $18.85 \pm 0.36$ \\
& 18 & 13.15 & $11.10 \pm 0.03$ & $12.22 \pm 0.10$ \\
& 22 & 17.15 & $8.38 \pm 0.05$ & $9.08 \pm 0.08$ \\
Western brook lamprey & 10 & 5.03 & $26.93 \pm 0.53$ & $29.34 \pm 0.60$ \\
& 14 & 9.03 & $15.82 \pm 0.18$ & $17.00 \pm 0.19$ \\
& 18 & 13.03 & $10.84 \pm 0.10$ & $11.90 \pm 0.06$ \\
& 22 & 17.03 & $8.05 \pm 0.10$ & $9.03 \pm 0.09$ \\
\hline
\end{tabular}


Table 5: NOAA Fisheries river lamprey catch records for 2002 in Skagit Bay, WA. Lampreys were captured as incidental catch during surface trawls using a $6 \mathrm{~m}$ (wide) by $3 \mathrm{~m}$ (deep) tow net.

\begin{tabular}{|c|c|c|c|c|c|c|c|c|c|c|c|c|c|}
\hline Date & $\begin{array}{l}\text { North } \\
\text { Hope } \\
\text { Island }\end{array}$ & $\begin{array}{l}\text { South } \\
\text { Hope } \\
\text { Island }\end{array}$ & $\begin{array}{l}\text { Lone } \\
\text { Tree } \\
\text { Point }\end{array}$ & $\begin{array}{c}\text { Similk } \\
\text { Bay }\end{array}$ & $\begin{array}{l}\text { South } \\
\text { Fork } \\
\text { Flats }\end{array}$ & $\begin{array}{c}\text { Strawberry } \\
\text { Point }\end{array}$ & $\begin{array}{c}\text { Dugualla } \\
\text { Bay }\end{array}$ & $\begin{array}{l}\text { North } \\
\text { Fork } \\
\text { Flats }\end{array}$ & Utsalady & $\begin{array}{l}\text { PBD } \\
\text { Flats }\end{array}$ & $\begin{array}{l}\text { Snee } \\
\text { Oosh }\end{array}$ & $\begin{array}{c}\text { Hoypus } \\
\text { Point }\end{array}$ & $\begin{array}{c}\text { Crescent } \\
\text { Harbor }\end{array}$ \\
\hline 04/10/2002 & 1 & & & & & & & & & & & & \\
\hline 06/03/2002 & 4 & & & & & & & & & & & & \\
\hline 06/04/2002 & & & 1 & 13 & 4 & 23 & & & & & & & \\
\hline $06 / 05 / 2002$ & & & & & & & 4 & 3 & 2 & & & & \\
\hline $07 / 10 / 2002$ & & & 7 & & & & 4 & & & 3 & & & \\
\hline $07 / 11 / 2002$ & & 1 & & 2 & & & & & & & 2 & 3 & \\
\hline $07 / 12 / 2002$ & & & & & 6 & 1 & & 7 & 2 & & & & 6 \\
\hline $07 / 30 / 2002$ & & & & & 5 & 1 & & & 3 & & & & 4 \\
\hline $07 / 31 / 2002$ & 1 & 1 & & & & & 1 & & & & & & \\
\hline 08/01/2002 & & & 4 & 24 & & & & & & & 1 & & \\
\hline 08/28/2002 & & & & 1 & & & 1 & & & & & & \\
\hline 08/29/2002 & & & 1 & & & & & & & & & & \\
\hline $10 / 30 / 2002$ & & & & & & & 1 & & & & & & \\
\hline Total & 6 & 2 & 13 & 40 & 15 & 25 & 11 & 10 & 7 & 3 & 3 & 3 & 10 \\
\hline
\end{tabular}



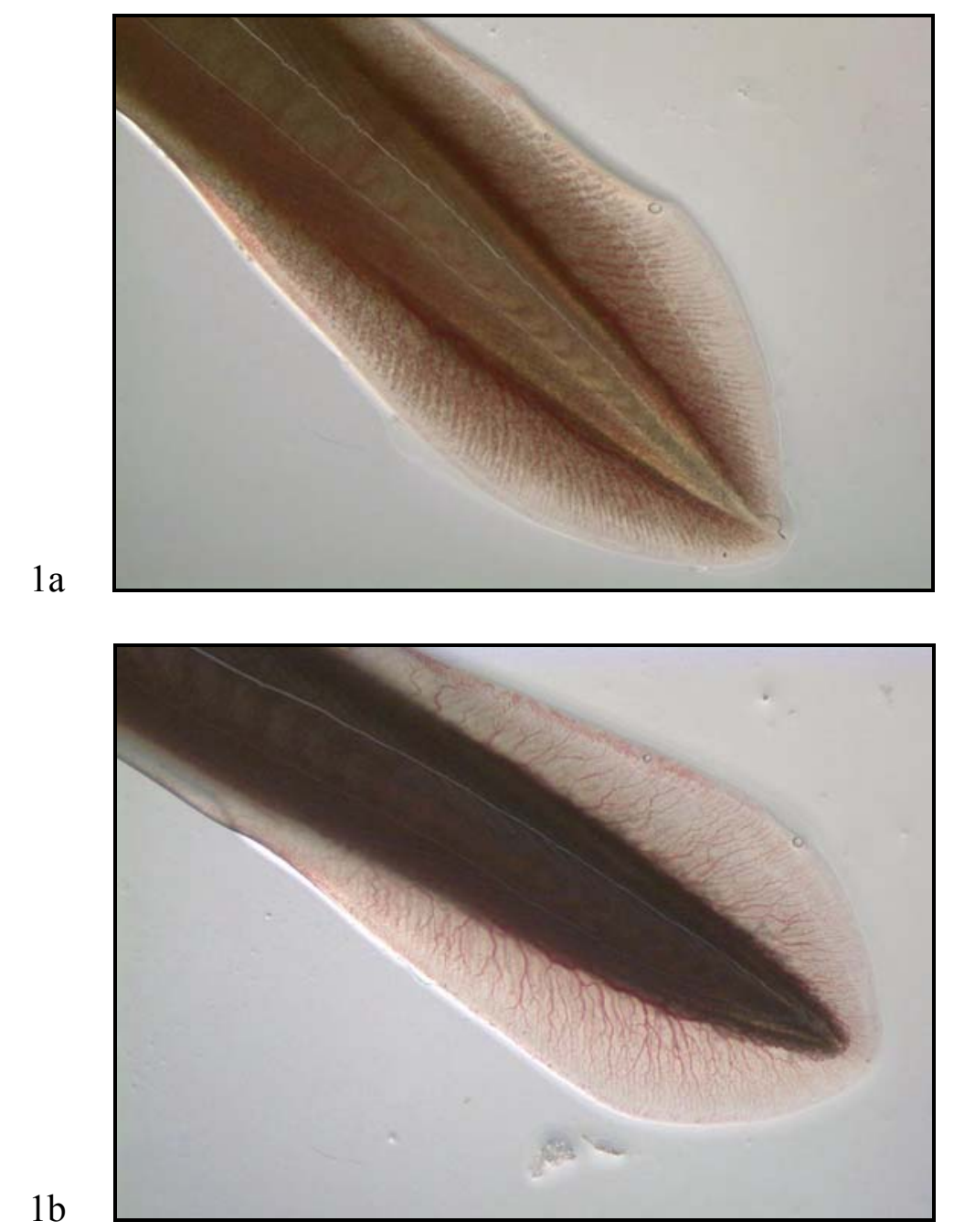

Figure 1: Examples of digital images of caudal region of: 1a) Pacific lamprey; characterized by light pigmentation along the caudal ridge, and $1 \mathrm{~b}$ ) western brook lamprey; characterized by dark, even pigmentation along the caudal ridge (Richards et al. 1982). 

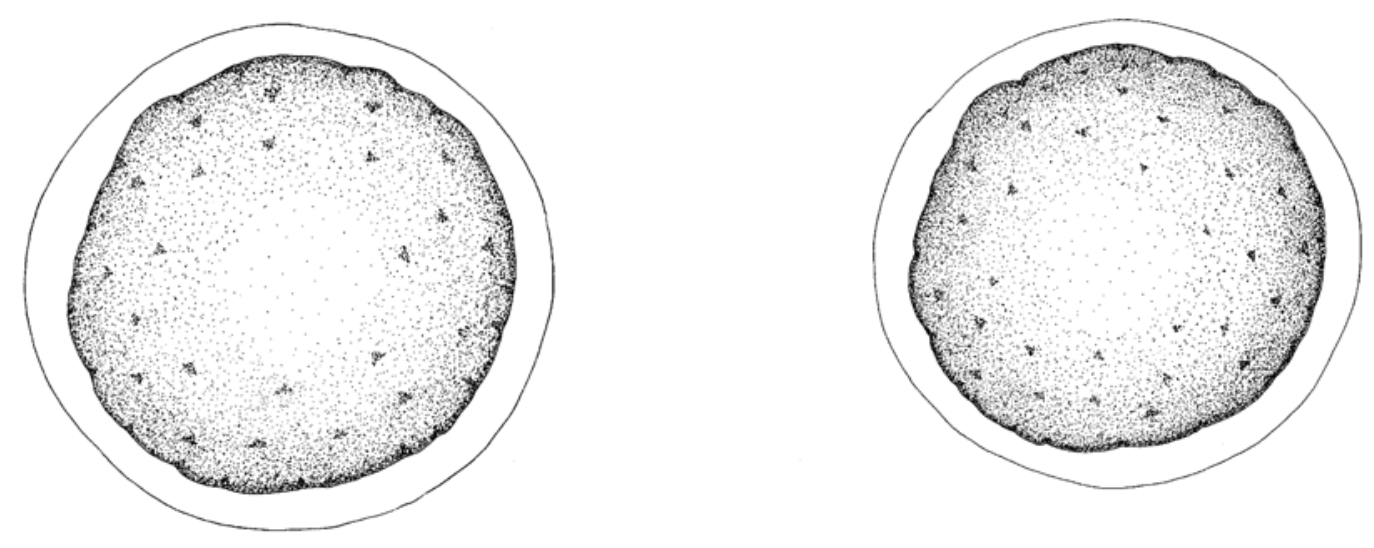

$2 \mathrm{a}$

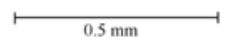

$2 b$

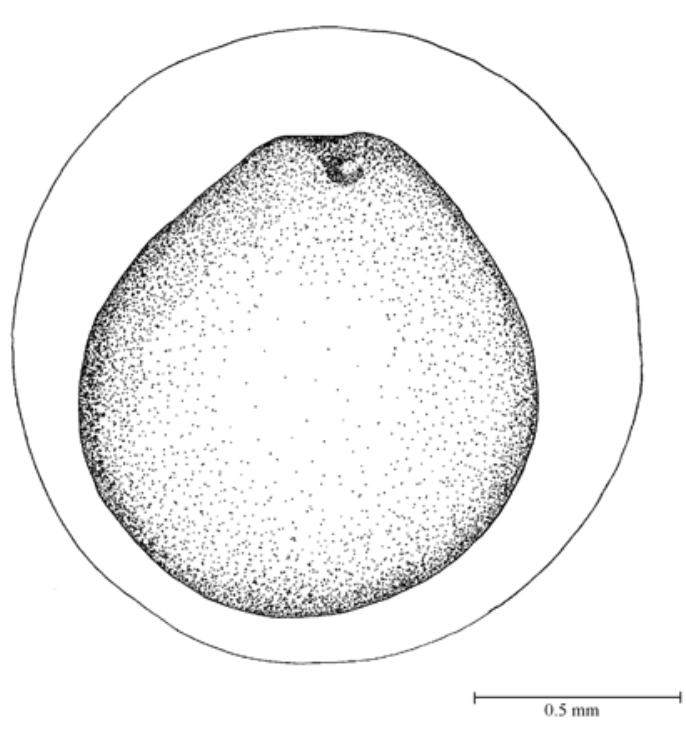

$2 \mathrm{c}$

$2 d$

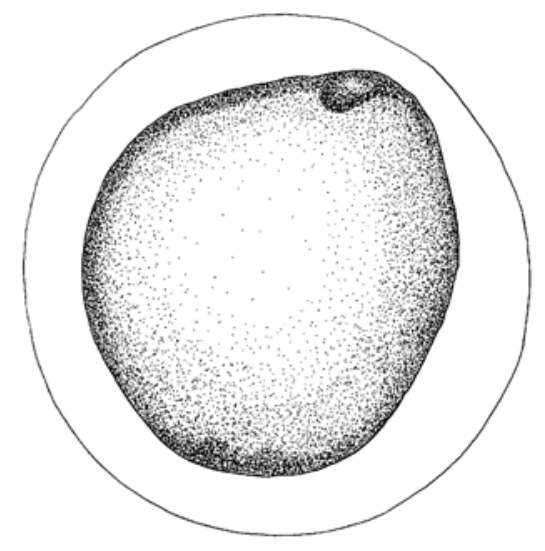

Figure2: Continued on the following page. 


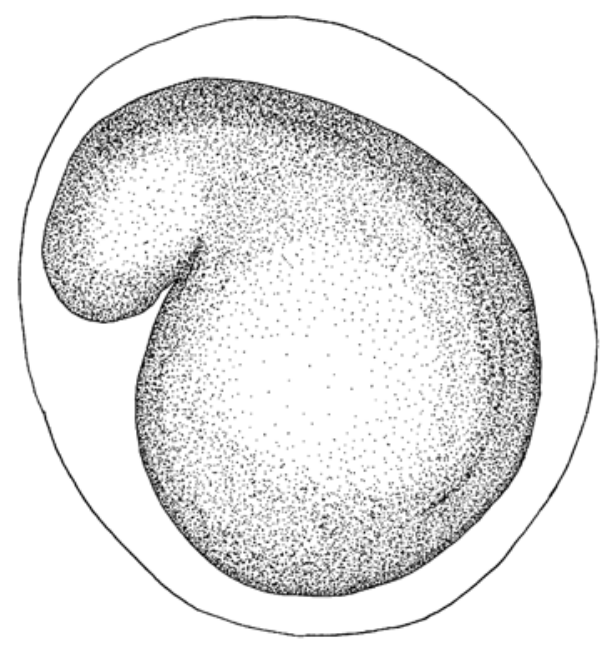

$2 \mathrm{e}$

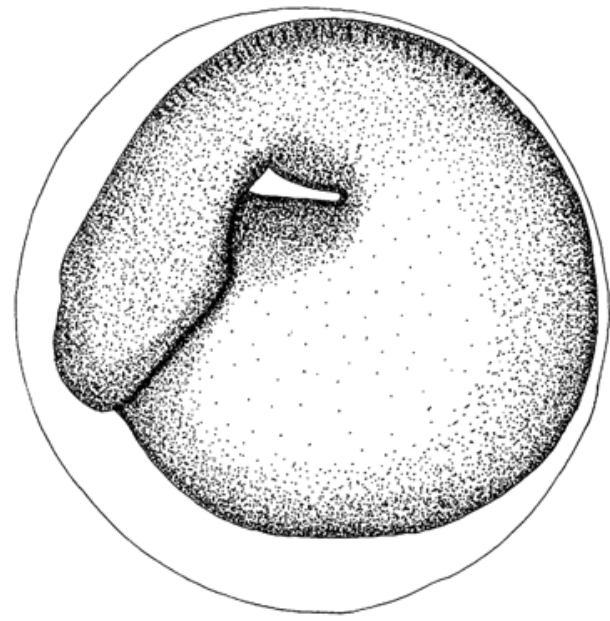

$2 \mathrm{~g}$

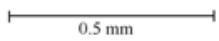

$2 \mathrm{f}$
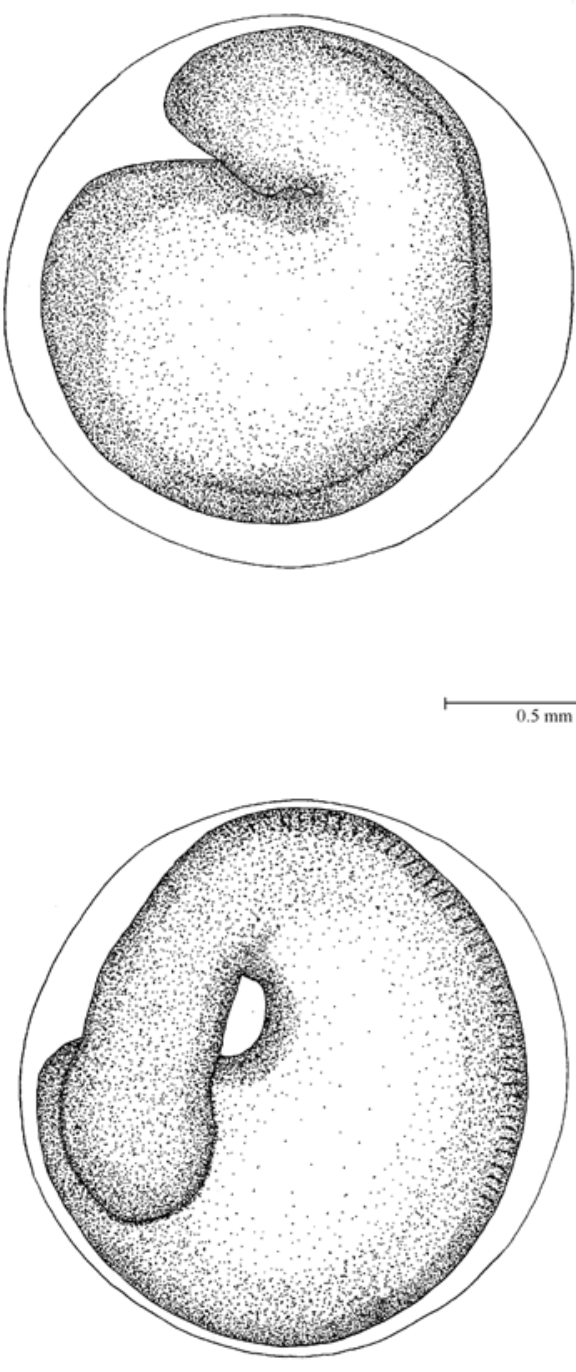

$2 \mathrm{~h}$

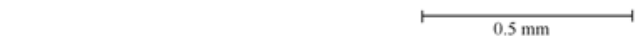

Figure 2: Time series of Pacific and western brook lamprey embryos reared at $14^{\circ} \mathrm{C}$; day 1 Pacific (2a) and western brook (2b) lamprey, day 7 Pacific (2c) and western brook (2d) lamprey, day 10 Pacific (2e) and western brook (2f) lamprey, and day 14 Pacific (2g) and western brook (2h) lamprey. 


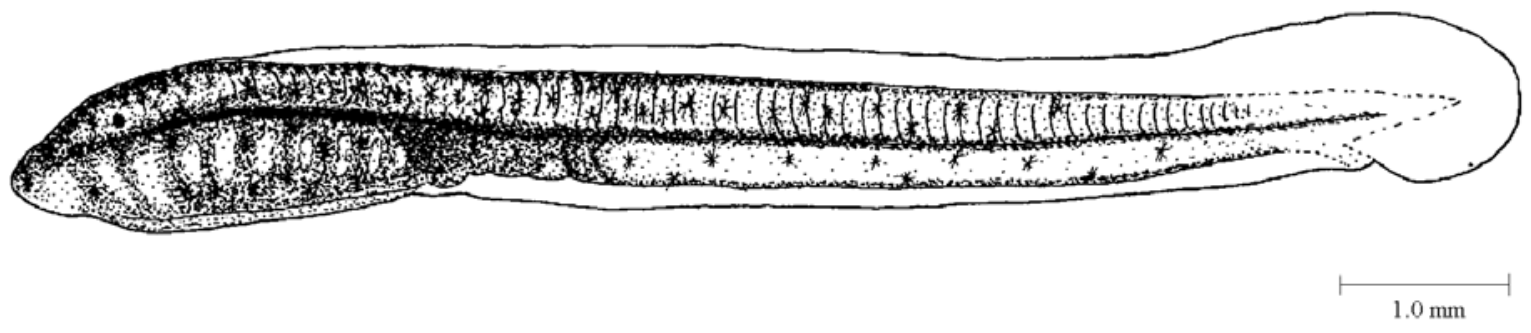

$3 a$

$3 b$
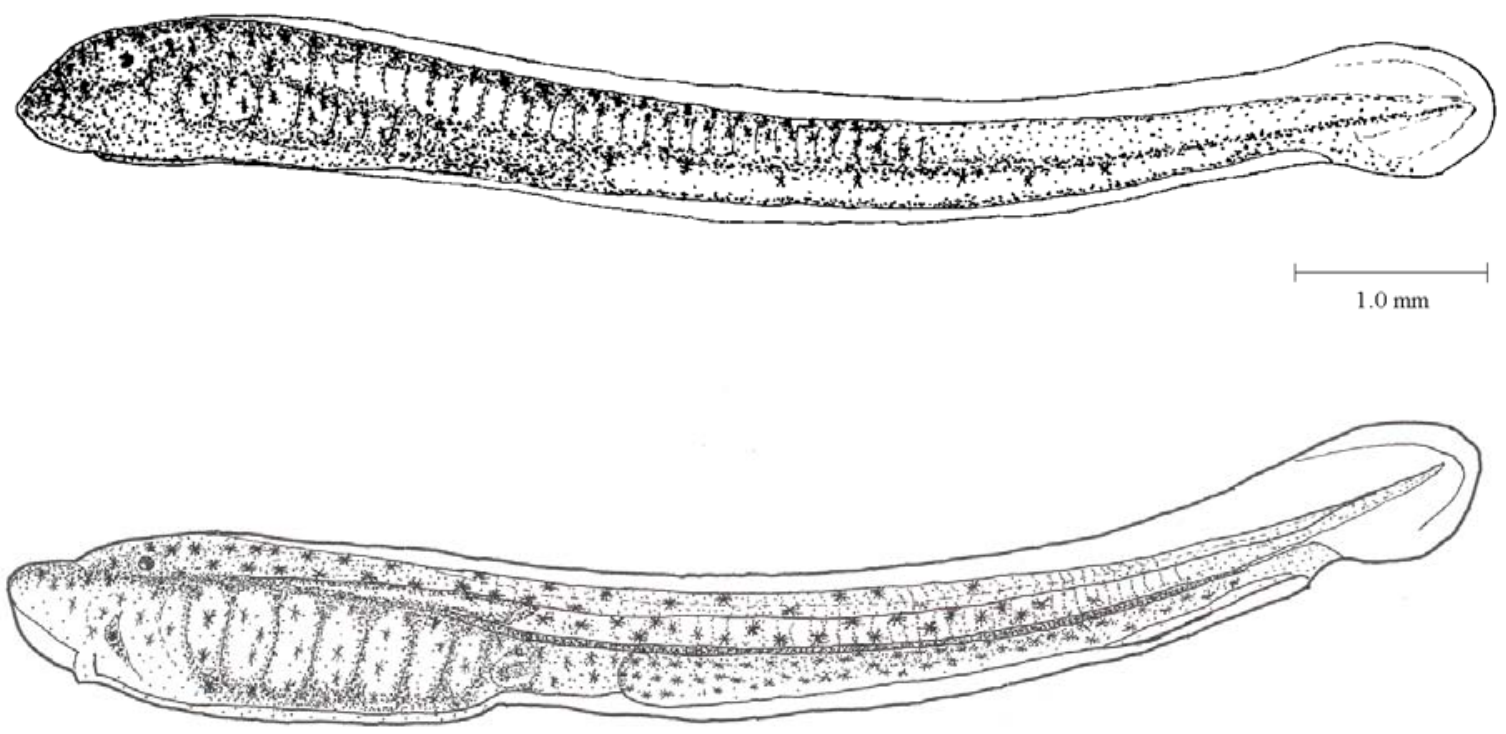

$3 \mathrm{c}$

$1.0 \mathrm{~mm}$

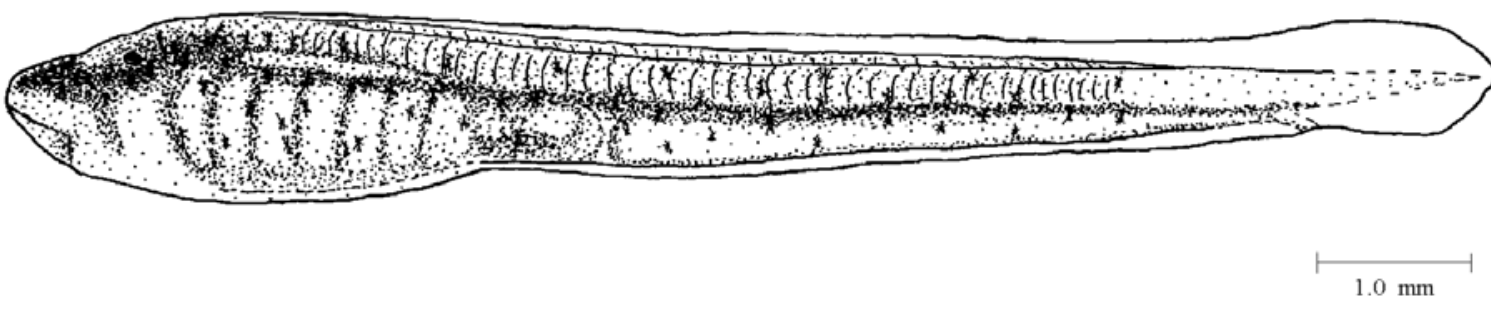

$3 d$

Figure 3: Line drawing of stage 17 Pacific lamprey (3a), stage 17 western brook lamprey (3b), stage 18 Pacific lamprey (3c), and stage 18 western brook lamprey (3d). 

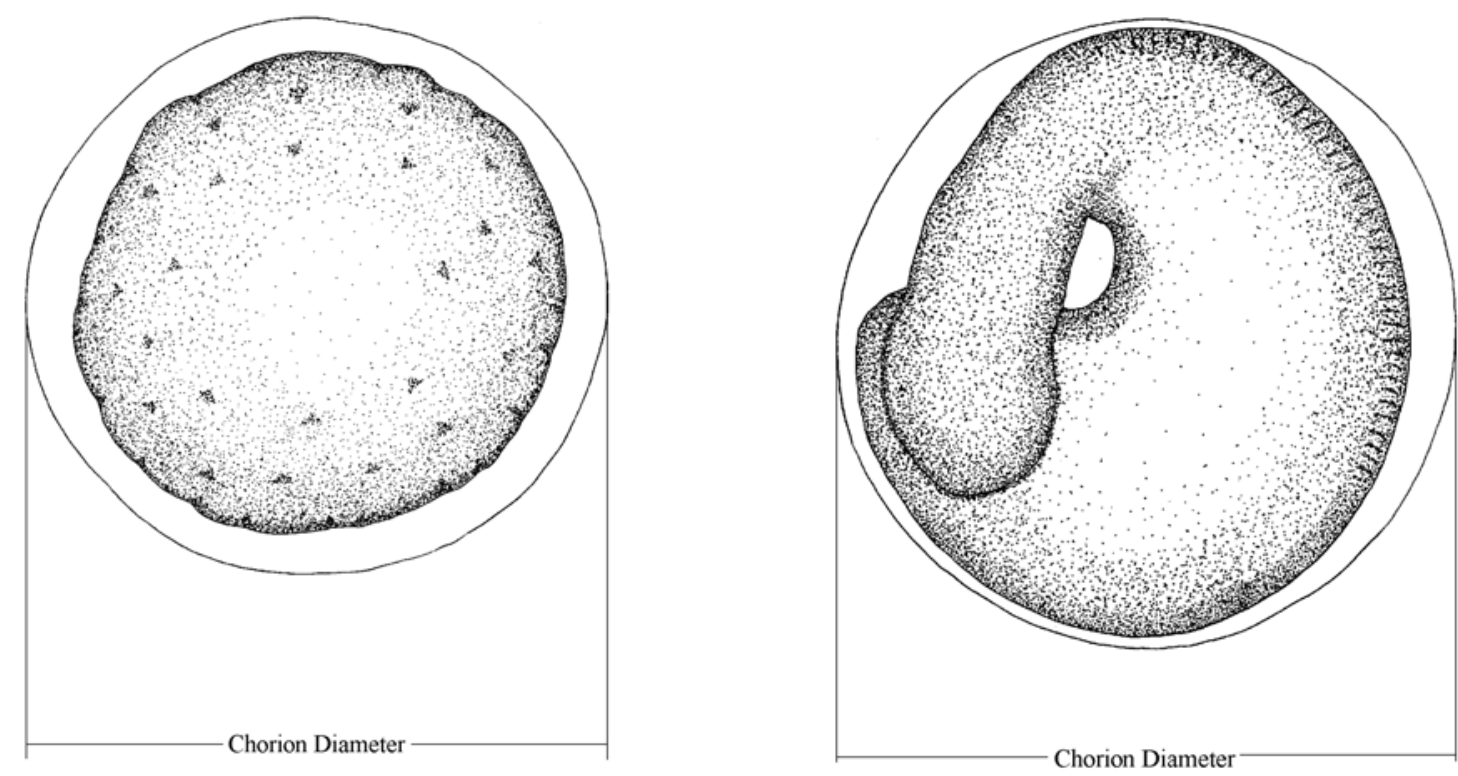

Figure 4: Line drawings of lamprey embryos indicating the chorion diameter. For each individual, 180 measurements where made through the embryo's centroid at 2 degree intervals and the mean chorion diameter was calculated. 


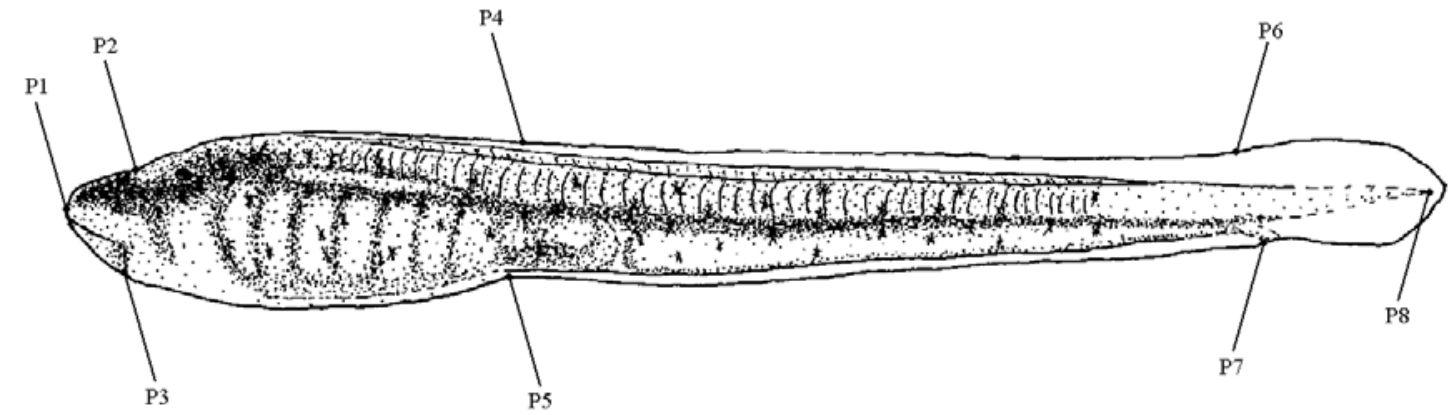

$5 \mathrm{a}$

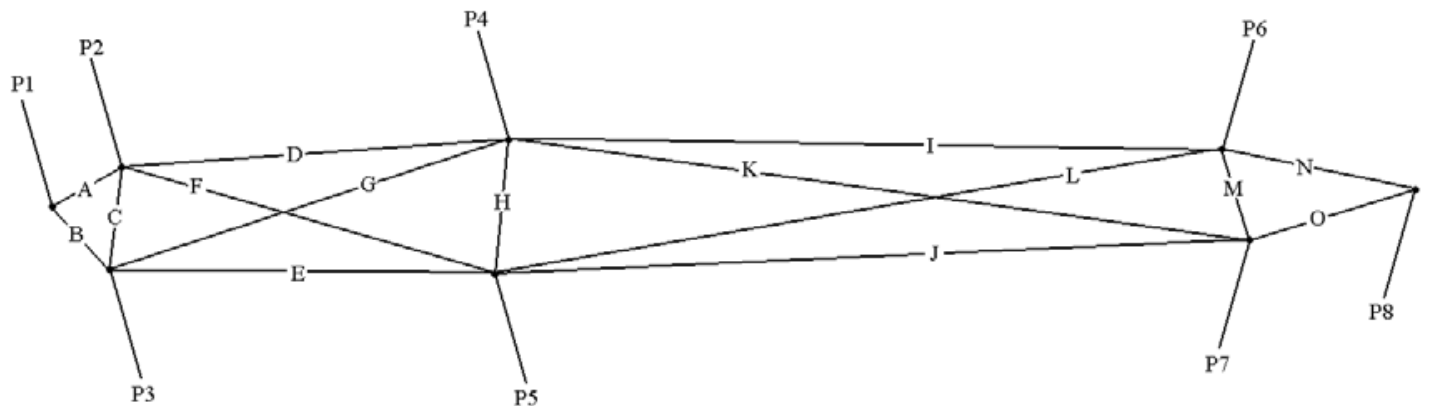

$5 b$

Figure 5: Line drawing of a larval lamprey indicating the locations of the eight homologous landmarks (5a), and a representation of the structure of the two-cell truss network with two appended triangles $(5 b)$. 


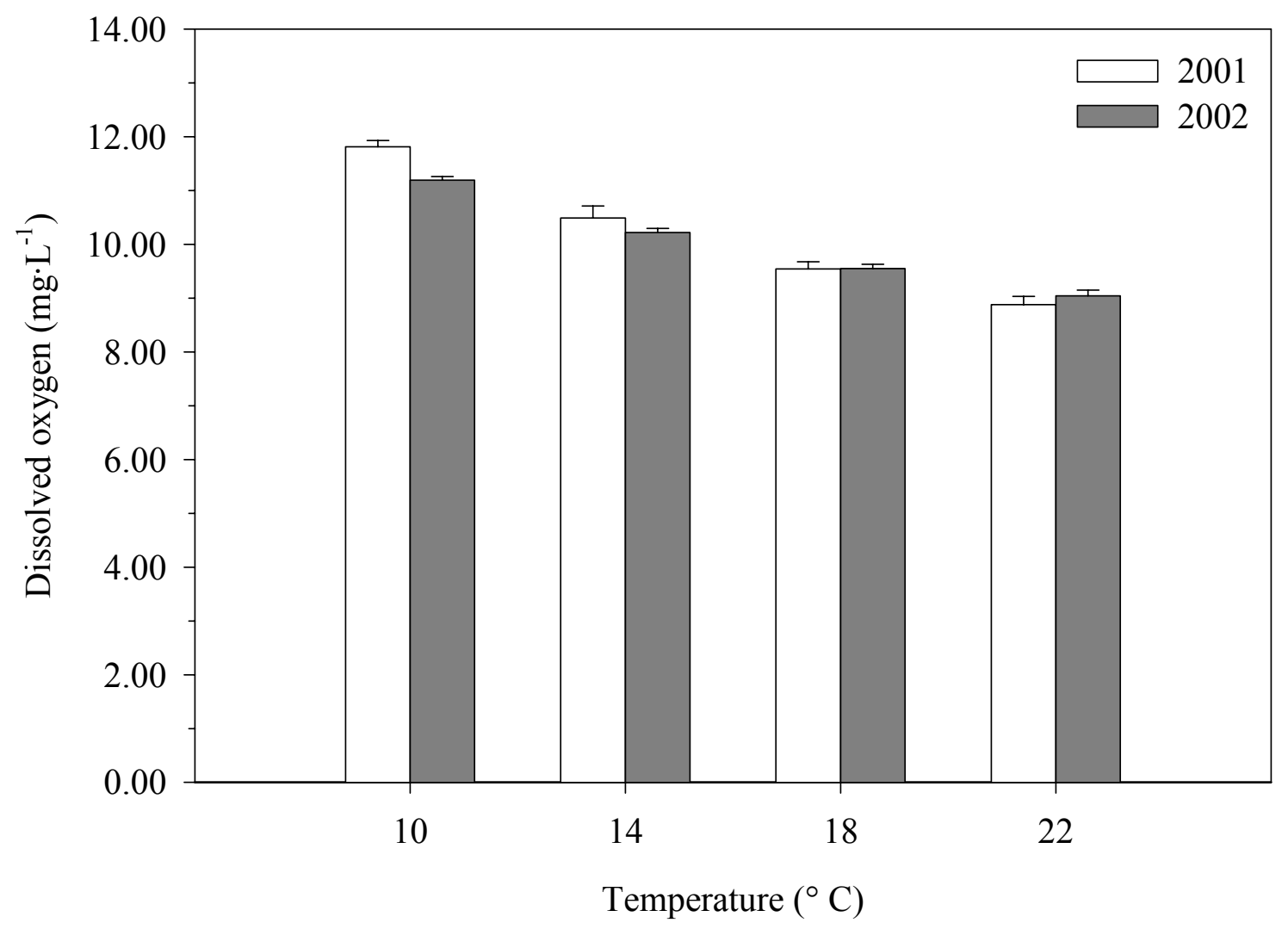

Figure 6: Mean dissolved oxygen $\left(\mathrm{mg} \cdot \mathrm{L}^{-1}\right)(+\mathrm{SE})$ of water baths at $10^{\circ} \mathrm{C}, 14^{\circ} \mathrm{C}, 18^{\circ} \mathrm{C}$, and $22^{\circ}$ $\mathrm{C}$ for experiments conducted in 2001 and 2002. Measurements were taken daily for the duration of the experiments. 


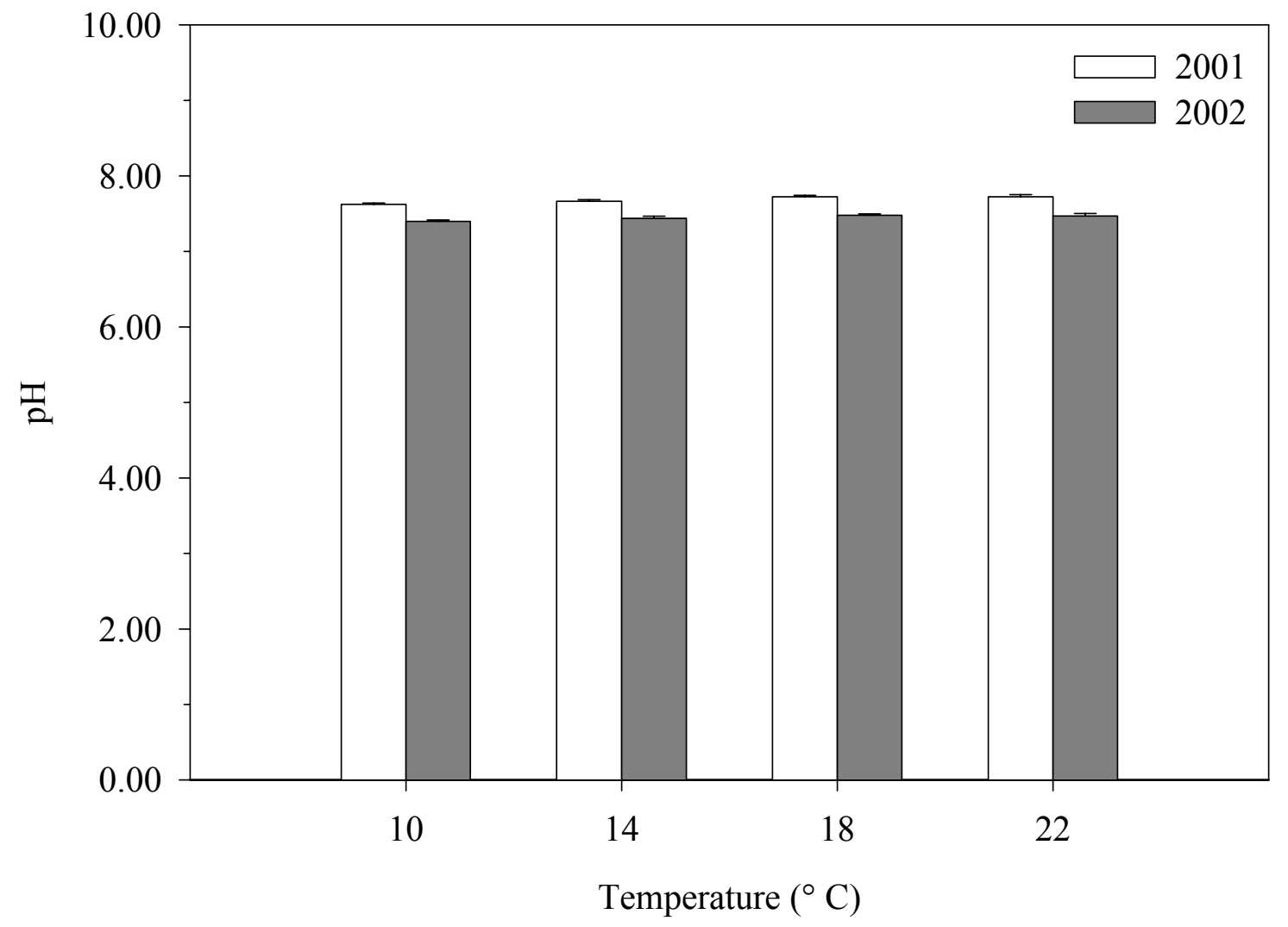

Figure 7: Mean $\mathrm{pH}(+\mathrm{SE})$ of water baths at $10^{\circ} \mathrm{C}, 14^{\circ} \mathrm{C}, 18^{\circ} \mathrm{C}$, and $22^{\circ} \mathrm{C}$ for experiments conducted in 2001 and 2002. Measurements were taken daily for the duration of the experiments. 


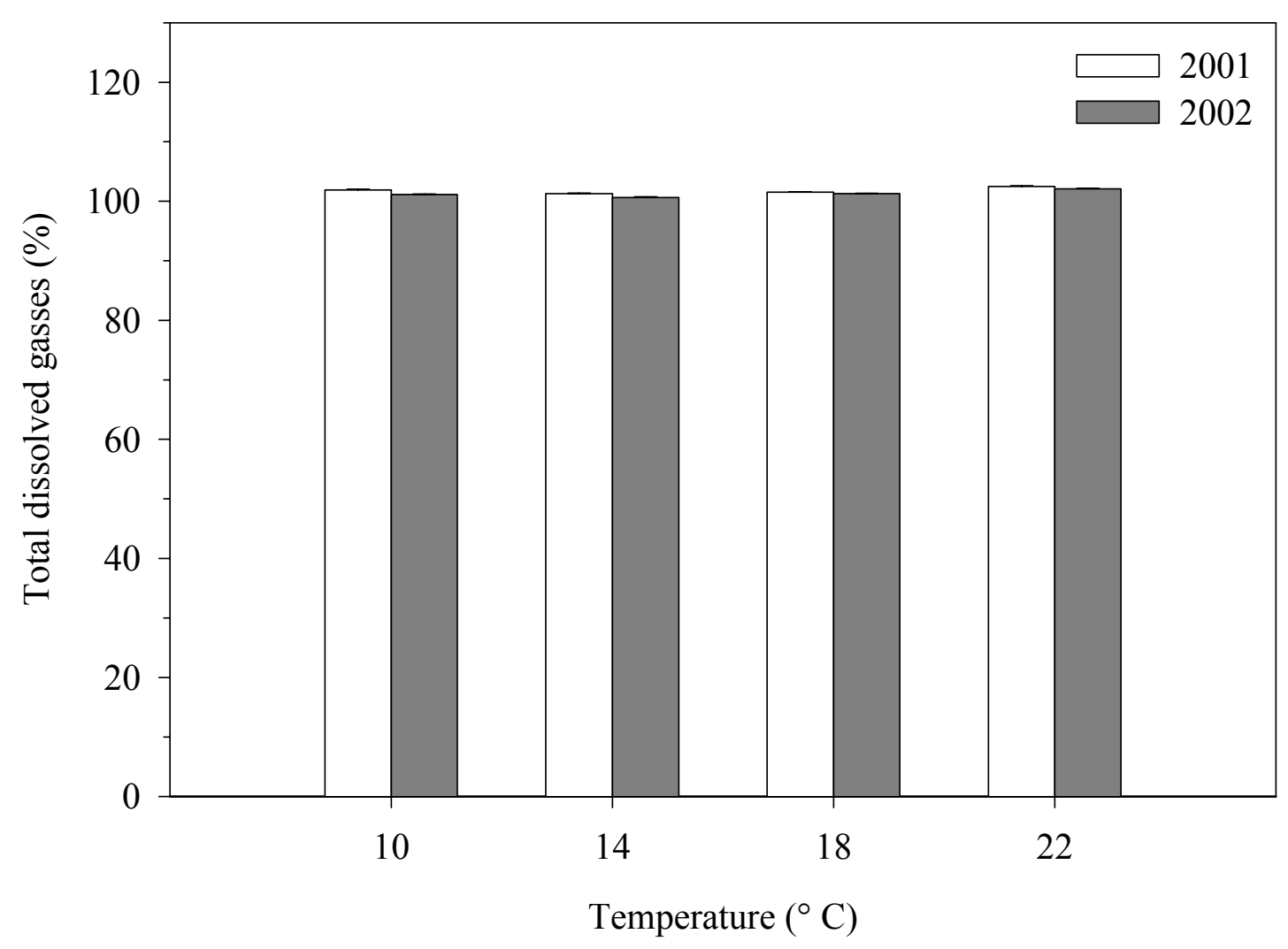

Figure 8: Mean total dissolved gasses (\% saturation) (+ SE) of water baths at $10^{\circ} \mathrm{C}, 14^{\circ} \mathrm{C}, 18^{\circ}$ $\mathrm{C}$, and $22^{\circ} \mathrm{C}$ for experiments conducted in 2001 and 2002. Measurements were taken daily for the duration of the experiments. 


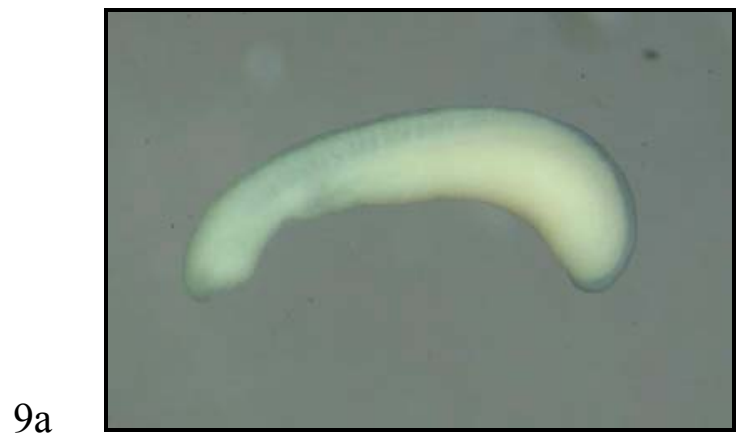

$9 \mathrm{~b}$
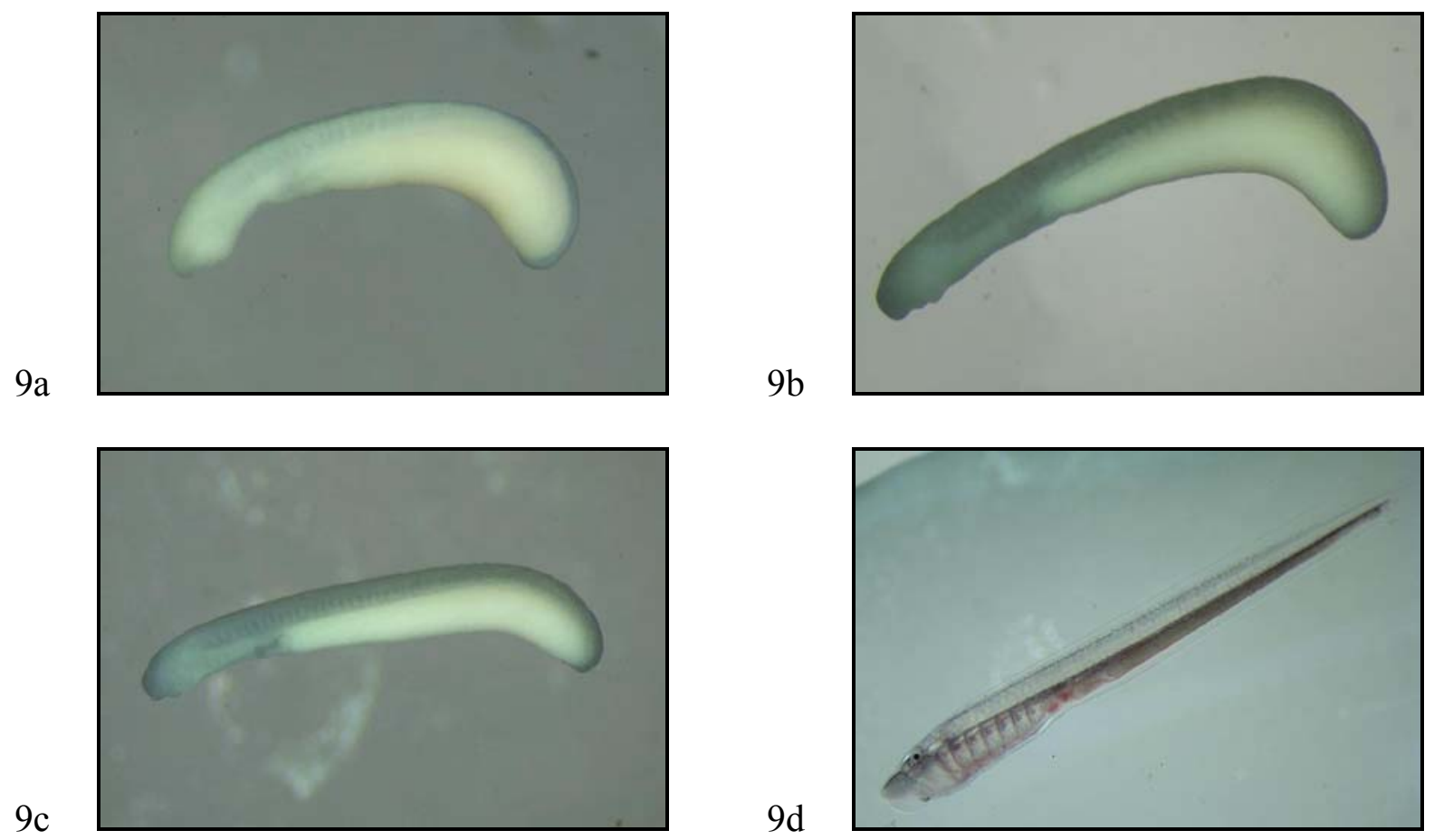

Figure 9: Time series of normal larval development of Columbia River Basin lampreys; 9a) recently hatched larva exhibiting well-pronounced ventral flexion, 9b) less pronounced ventral flexion, 9c) slight ventral flexion in posterior region, and 9d) fully developed larva. 

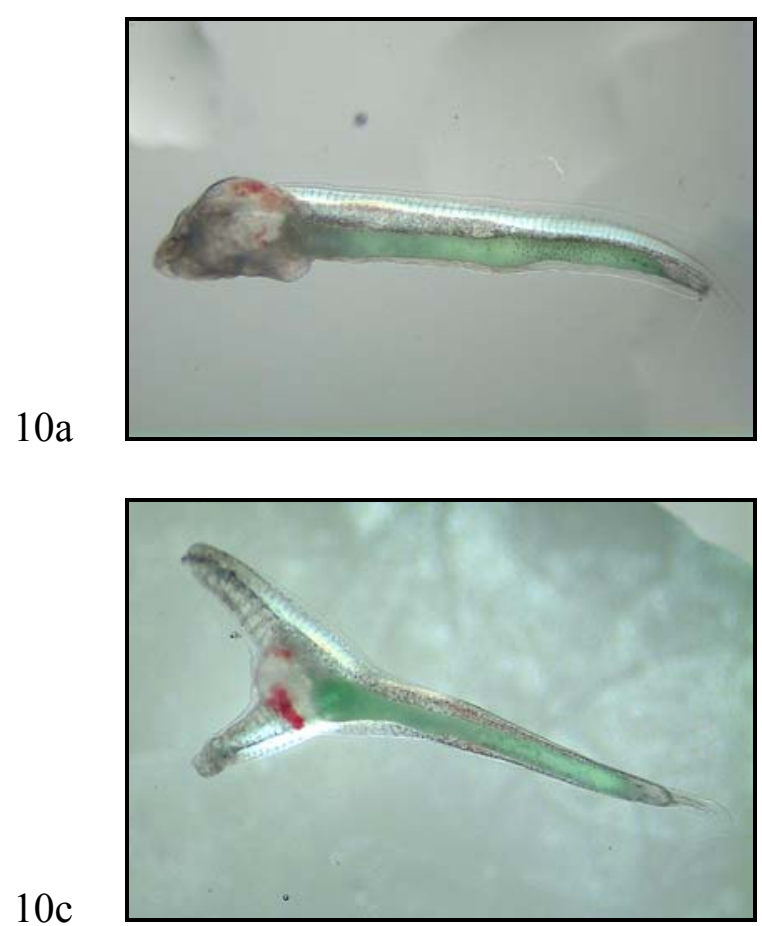

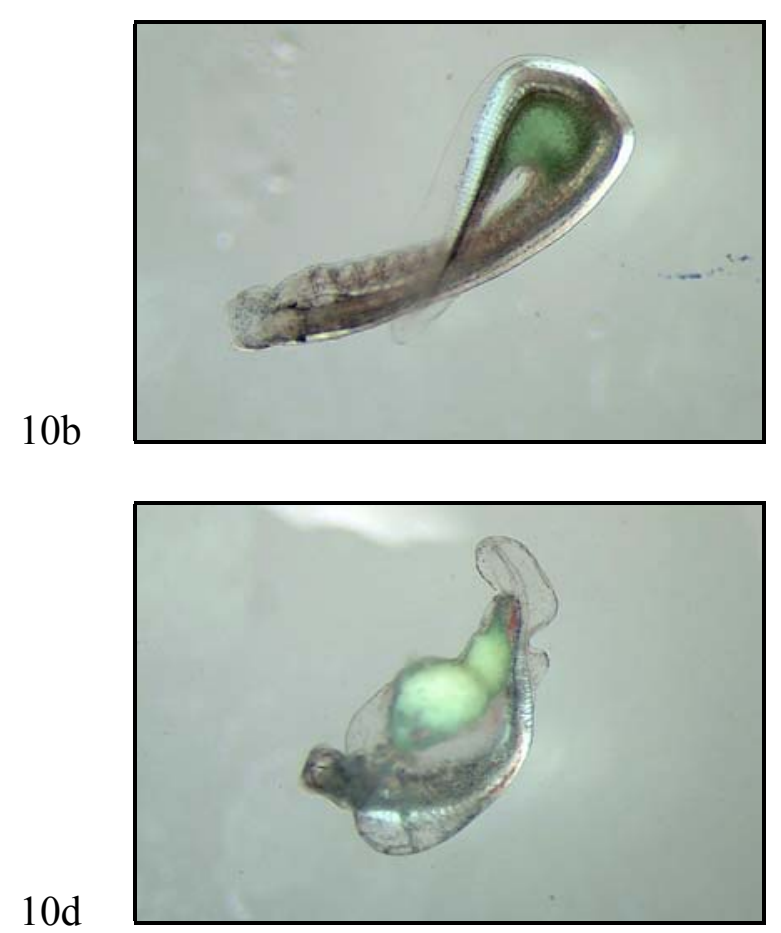

Figure 10: Series of abnormal Columbia River Basin lamprey larvae; 10a) larva with malformed head, branchial, and trunk regions, 10b) larva with malformed trunk region, 10c) larva with superfluous head and branchial region, and 10d) larva with extreme morphological malformations. 


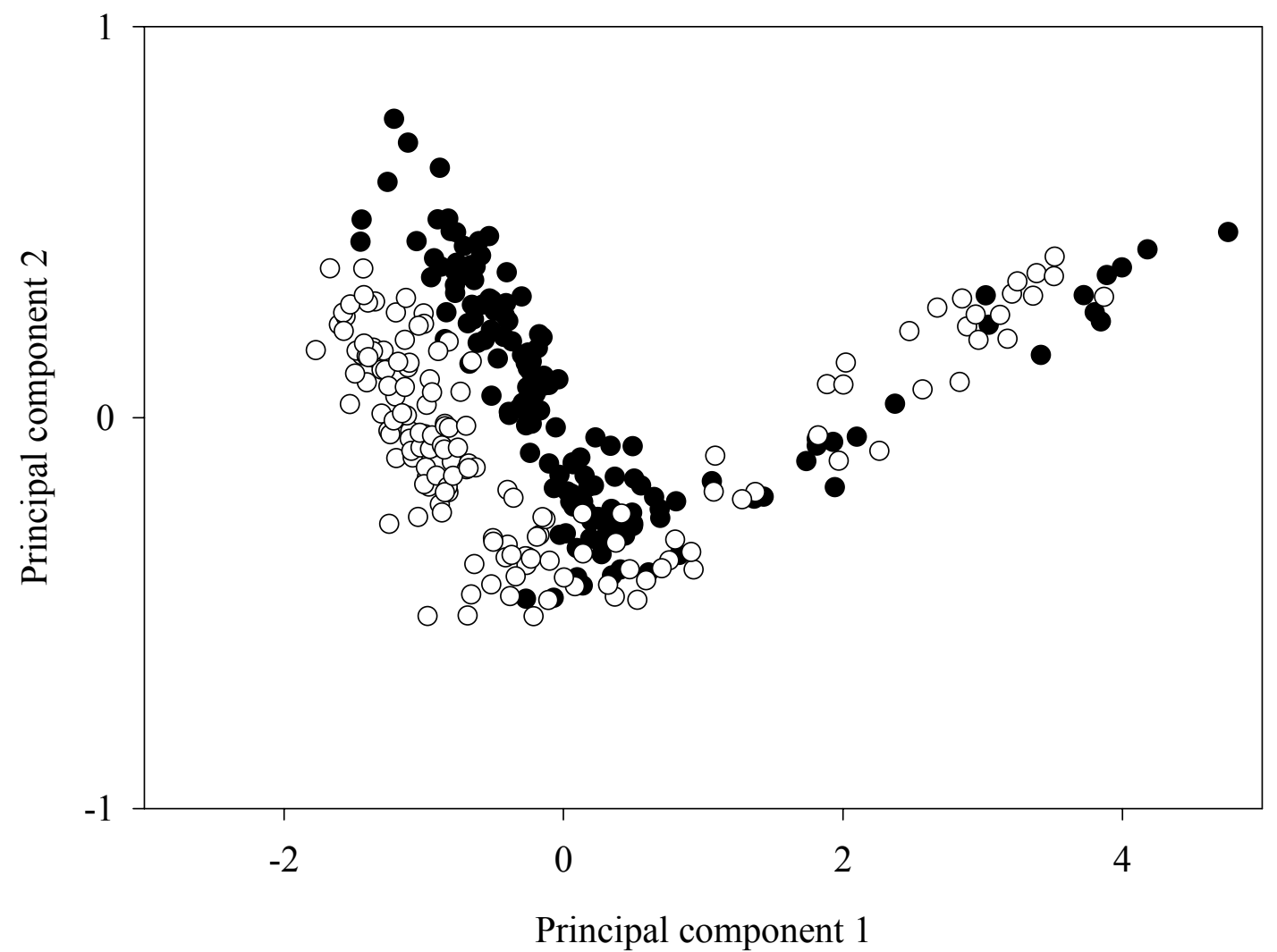

Figure 11: Components plot for principal components 1 and 2 associated with larval length measurements (log transformed standard length and truss elements). Filled circles $(\bullet)$ represent Pacific lampreys and empty circles (०) represent western brook lampreys. 


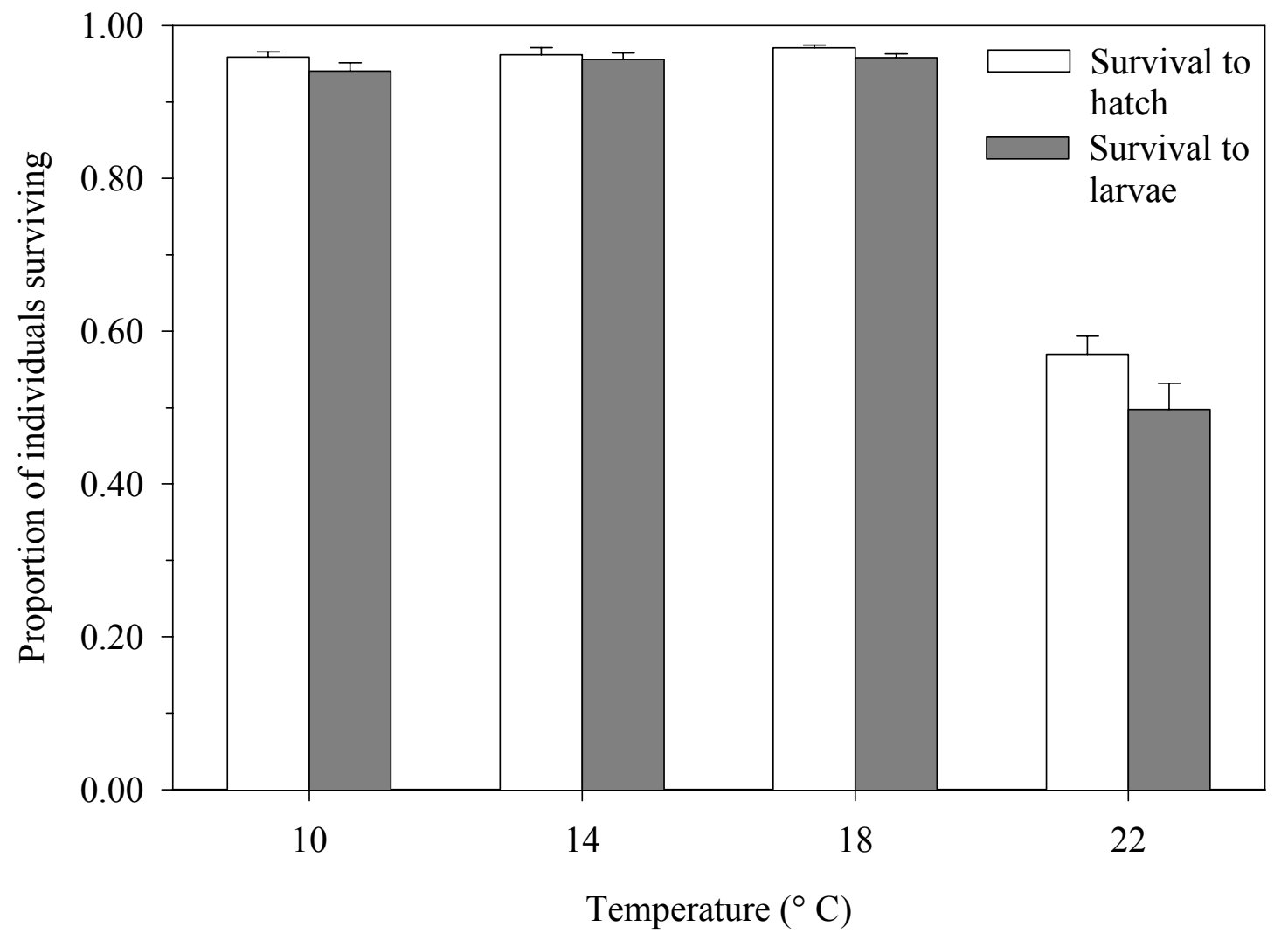

Figure 12: Proportion of individuals surviving $(+1 \mathrm{SE})$ at hatch $\left(S_{\mathrm{H}}\right)$ and at the larval stage $\left(S_{\mathrm{L}}\right)$. Overall, survival was significantly reduced at $22^{\circ} \mathrm{C}$ when compared to other temperatures. 


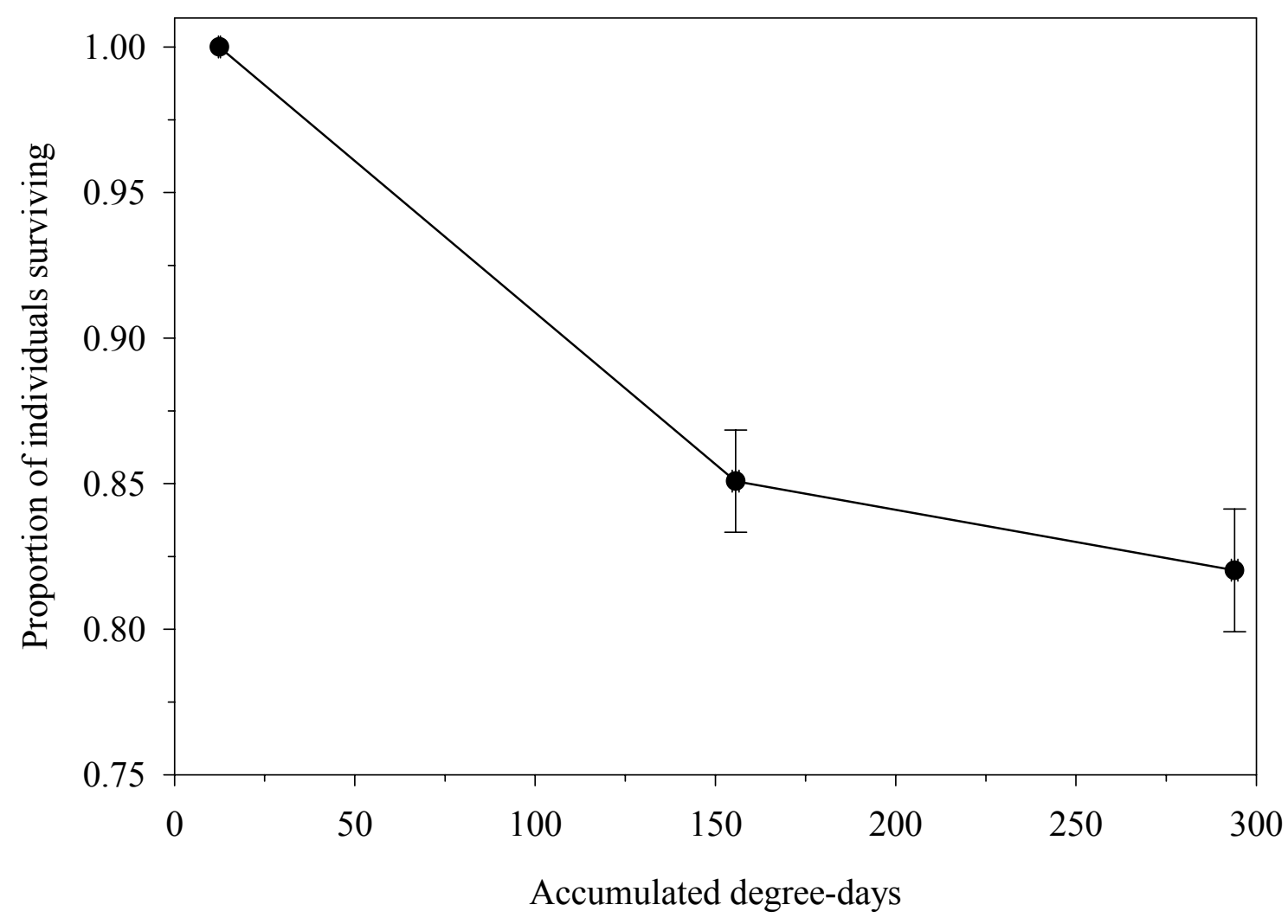

Figure 13: Trend in the proportion of individuals surviving ( $\pm 1 \mathrm{SE})$ from the initiation of experiment $(12.5 D D)$ to hatch $(155.6 D D)$ and from hatch to the larval stage $(294.0 D D)$. A slight, but significant, decrease in survival was observed from the time of hatch to the larval stage. 


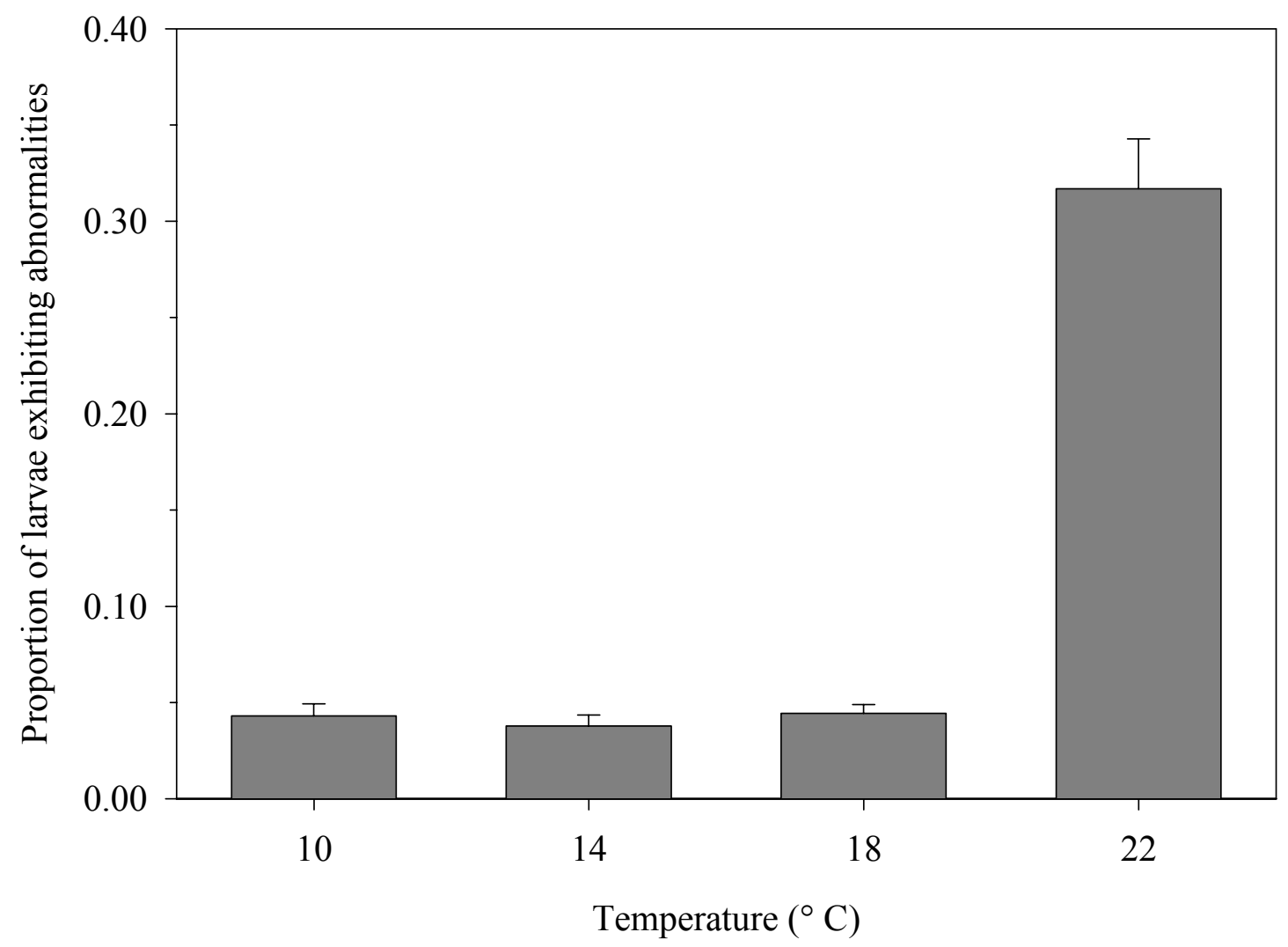

Figure 14: Proportion of larvae exhibiting abnormalities (+ $1 \mathrm{SE})$. Significantly more larvae exhibited abnormalities at $22^{\circ} \mathrm{C}$ when compared to other temperatures. 


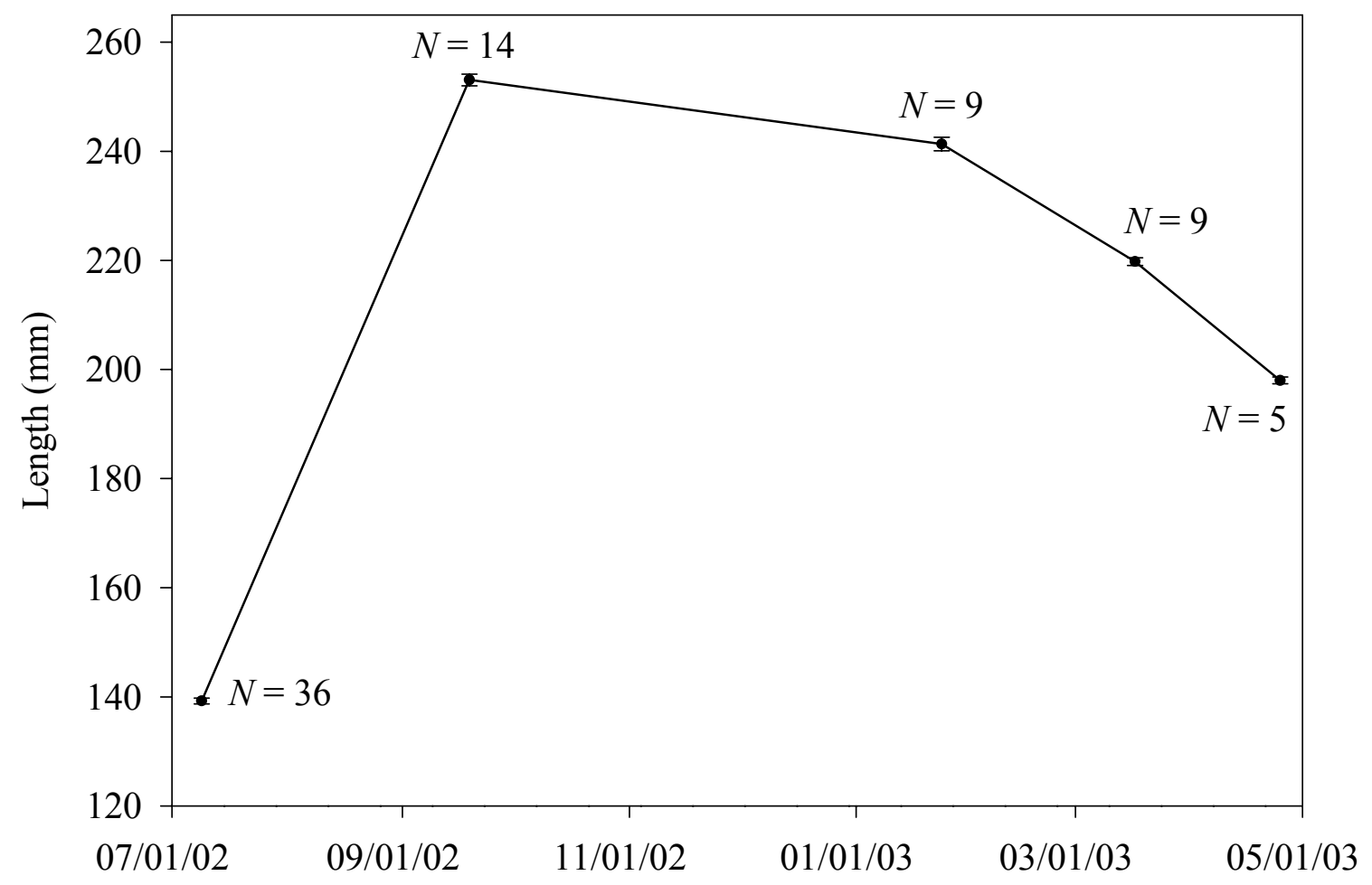

Date

Figure 15: Mean total length $(\mathrm{mm} \pm 1 \mathrm{SE})$ and sample size for river lampreys held in captivity and measured at intervals from July 2002 until April 2003. 


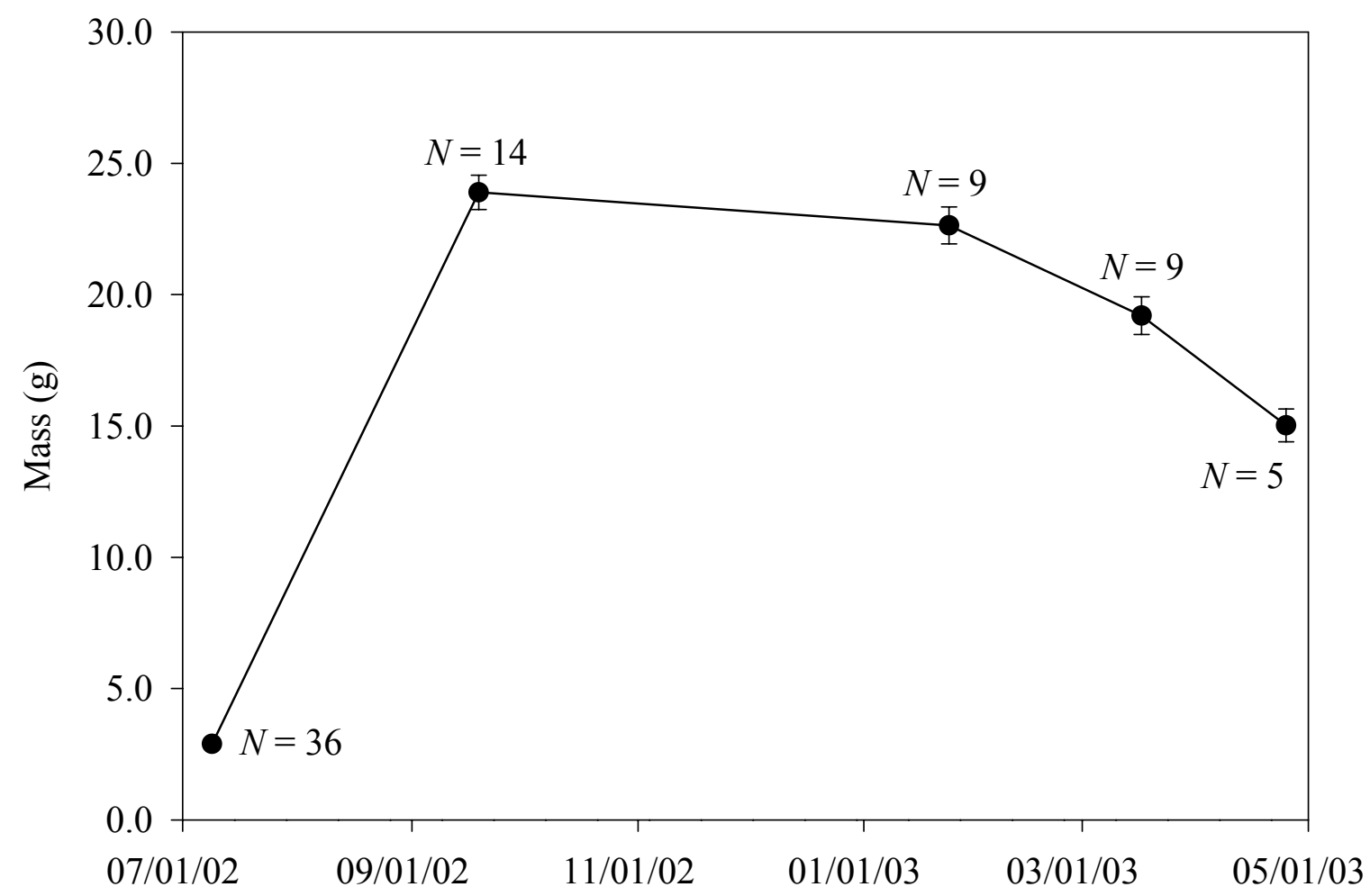

Date

Figure 16: Mean wet mass $(\mathrm{g} \pm 1 \mathrm{SE})$ and sample size for river lampreys held in captivity and measured at intervals from July 2002 until April 2003. 
Appendix 1: Sample number, collection location, length $(\mathrm{mm})$, mass (g), and preliminary species identification based on current diagnostic characteristics for lamprey larvae sacrificed for genetic analyses. Genetic confirmation of identification is not yet available (NYA). Collection location: ENT=Entiat River, JDW=John Day/Walla Walla Rivers, RED=Red River, and CED=Cedar Creek. Preliminary species identification: $\mathrm{PCL}=$ Pacific lamprey and $\mathrm{WBL}=$ western brook lamprey.

\begin{tabular}{|c|c|c|c|c|c|}
\hline $\begin{array}{l}\text { Sample } \\
\text { Number }\end{array}$ & $\begin{array}{c}\text { Collection } \\
\text { location }\end{array}$ & Length (mm) & Mass (g) & $\begin{array}{c}\text { Preliminary species } \\
\text { identification }\end{array}$ & $\begin{array}{c}\text { Genetic } \\
\text { confirmation }\end{array}$ \\
\hline 1 & ENT & 130 & 3.481 & PCL & NYA \\
\hline 2 & ENT & 126 & 2.824 & PCL & NYA \\
\hline 3 & ENT & 134 & 3.555 & PCL & NYA \\
\hline 4 & ENT & 133 & 3.631 & PCL & NYA \\
\hline 5 & ENT & 137 & 3.997 & PCL & NYA \\
\hline 6 & ENT & 123 & 3.125 & PCL & NYA \\
\hline 7 & ENT & 127 & 3.427 & PCL & NYA \\
\hline 8 & ENT & 145 & 4.277 & PCL & NYA \\
\hline 9 & ENT & 134 & 3.955 & PCL & NYA \\
\hline 10 & ENT & 141 & 3.593 & PCL & NYA \\
\hline 11 & ENT & 143 & 4.161 & PCL & NYA \\
\hline 12 & ENT & 130 & 3.441 & PCL & NYA \\
\hline 13 & JDW & 148 & 4.840 & WBL & NYA \\
\hline 14 & JDW & 131 & 3.501 & WBL & NYA \\
\hline 15 & JDW & 124 & 2.950 & PCL & NYA \\
\hline 16 & JDW & 126 & 3.086 & WBL & NYA \\
\hline 17 & JDW & 146 & 4.765 & WBL & NYA \\
\hline 18 & JDW & 143 & 4.337 & WBL & NYA \\
\hline 19 & JDW & 127 & 3.136 & PCL & NYA \\
\hline 20 & JDW & 138 & 3.089 & WBL & NYA \\
\hline 21 & JDW & 130 & 3.858 & PCL & NYA \\
\hline 22 & JDW & 129 & 3.471 & PCL & NYA \\
\hline 23 & JDW & 128 & 3.280 & PCL & NYA \\
\hline 24 & JDW & 132 & 3.567 & WBL & NYA \\
\hline 25 & JDW & 132 & 3.521 & WBL & NYA \\
\hline 26 & JDW & 115 & 2.507 & PCL & NYA \\
\hline 27 & RED & 141 & 4.560 & PCL & NYA \\
\hline 28 & RED & 152 & 5.551 & PCL & NYA \\
\hline 29 & RED & 141 & 4.543 & PCL & NYA \\
\hline 30 & RED & 122 & 2.772 & PCL & NYA \\
\hline 31 & RED & 111 & 2.190 & PCL & NYA \\
\hline 32 & RED & 137 & 4.084 & PCL & NYA \\
\hline 33 & CED & 117 & 2.280 & PCL & NYA \\
\hline 34 & CED & 111 & 1.985 & PCL & NYA \\
\hline 35 & CED & 104 & 1.587 & PCL & NYA \\
\hline 36 & CED & 107 & 1.877 & PCL & NYA \\
\hline 37 & CED & 108 & 1.749 & PCL & NYA \\
\hline 38 & CED & 86 & 1.038 & PCL & NYA \\
\hline 39 & CED & 119 & 2.474 & PCL & NYA \\
\hline 40 & CED & 120 & 2.576 & PCL & NYA \\
\hline 41 & CED & 119 & 2.439 & PCL & NYA \\
\hline 42 & CED & 113 & 2.062 & PCL & NYA \\
\hline 43 & CED & 97 & 1.201 & PCL & NYA \\
\hline 44 & CED & 122 & 2.752 & PCL & NYA \\
\hline 45 & CED & 116 & 2.595 & PCL & NYA \\
\hline 46 & CED & 115 & 2.158 & PCL & NYA \\
\hline 47 & CED & 107 & 1.768 & PCL & NYA \\
\hline 48 & CED & 95 & 1.330 & PCL & NYA \\
\hline 49 & CED & 96 & 1.316 & PCL & NYA \\
\hline 50 & CED & 94 & 1.440 & PCL & NYA \\
\hline
\end{tabular}


Appendix 2: Number of sampling events (at approximately six week intervals), mean length (mm), mean mass (g), percent of sampling events where individual was identified as PCL (Pacific lamprey), percent of sampling events where individual was identified as WBL (western brook lamprey), and species identification, if confirmation was possible, for 31 individuals from four collection sites (CED = Cedar Creek, WA; ENT = Entiat River, WA; RED = Red River, WA; JDW = John Day River, OR/Walla Walla River, WA).

\begin{tabular}{|c|c|c|c|c|c|c|}
\hline $\begin{array}{l}\text { Collection } \\
\text { site }\end{array}$ & $\begin{array}{c}\text { Number of } \\
\text { sampling events }\end{array}$ & $\begin{array}{l}\text { Mean length } \\
(\mathrm{mm})\end{array}$ & $\begin{array}{c}\text { Mean mass } \\
(\mathrm{g})\end{array}$ & $\begin{array}{l}\text { Percent of events } \\
\text { identified as PCL }\end{array}$ & $\begin{array}{l}\text { Percent of events } \\
\text { identified as WBL }\end{array}$ & $\begin{array}{c}\text { Confirmed species } \\
\text { identification }\end{array}$ \\
\hline CED & 7 & 90 & 0.901 & 100 & 0 & \\
\hline CED & 11 & 109 & 1.560 & 100 & 0 & \\
\hline CED & 4 & 92 & 1.047 & 100 & 0 & \\
\hline CED & 11 & 85 & 0.849 & 100 & 0 & \\
\hline CED & 5 & 82 & 0.792 & 100 & 0 & \\
\hline CED & 13 & 85 & 0.859 & 100 & 0 & \\
\hline CED & 12 & 84 & 0.956 & 83 & 17 & \\
\hline CED & 14 & 94 & 1.108 & 100 & 0 & \\
\hline CED & 12 & 91 & 0.876 & 100 & 0 & \\
\hline RED & 11 & 135 & 3.589 & 100 & 0 & PCL \\
\hline RED & 30 & 127 & 2.859 & 100 & 0 & \\
\hline RED & 30 & 134 & 3.436 & 100 & 0 & \\
\hline RED & 30 & 126 & 2.684 & 100 & 0 & \\
\hline RED & 6 & 142 & 4.500 & 100 & 0 & \\
\hline RED & 30 & 139 & 3.581 & 100 & 0 & \\
\hline ENT & 30 & 128 & 2.977 & 100 & 0 & \\
\hline ENT & 30 & 123 & 2.450 & 100 & 0 & \\
\hline ENT & 13 & 108 & 1.713 & 100 & 0 & \\
\hline ENT & 18 & 124 & 2.919 & 100 & 0 & PCL \\
\hline ENT & 30 & 127 & 2.569 & 100 & 0 & \\
\hline ENT & 26 & 132 & 3.272 & 100 & 0 & \\
\hline ENT & 30 & 121 & 2.660 & 100 & 0 & \\
\hline ENT & 25 & 120 & 2.307 & 100 & 0 & \\
\hline JDW & 20 & 125 & 2.752 & 100 & 0 & \\
\hline JDW & 27 & 122 & 2.275 & 0 & 100 & \\
\hline JDW & 27 & 117 & 2.263 & 0 & 100 & \\
\hline JDW & 15 & 114 & 1.921 & 0 & 100 & \\
\hline JDW & 27 & 123 & 2.605 & 100 & 0 & \\
\hline JDW & 22 & 116 & 2.138 & 100 & 0 & \\
\hline JDW & 27 & 120 & 2.291 & 100 & 0 & \\
\hline JDW & 20 & 111 & 1.841 & 0 & 100 & \\
\hline
\end{tabular}


Appendix 3: Locations and descriptions of landmarks and truss elements used for morphometric descriptions of lampreys.

\begin{tabular}{ccl}
\hline Feature & Label & Description \\
\hline Landmark & P1 & Anterior most portion of the larva (snout) \\
Landmark & P2 & Dorsal margin of the oral hood and the head \\
Landmark & P3 & Anterior most portion of the transverse lip of the oral hood \\
Landmark & P4 & Point at the terminus of a line drawn from P5 to, and \\
& & perpendicular to, the dorsal surface of the larva \\
Landmark & P5 & Ventral margin of the branchial region and the trunk \\
Landmark & P6 & Point at the terminus of a line drawn from P7 to, and \\
& & perpendicular to, the dorsal surface of the larva \\
Landmark & P7 & Anterior most portion of the vent \\
Landmark & P8 & Posterior most portion of the notochord \\
Truss element & A & Line connecting P1 and P2 \\
Truss element & B & Line connecting P1 and P3 \\
Truss element & C & Line connecting P2 and P3 \\
Truss element & D & Line connecting P2 and P4 \\
Truss element & E & Line connecting P3 and P5 \\
Truss element & F & Line connecting P2 and P5 \\
Truss element & G & Line connecting P3 and P4 \\
Truss element & H & Line connecting P4 and P5 \\
Truss element & I & Line connecting P4 and P6 \\
Truss element & J & Line connecting P5 and P7 \\
Truss element & K & Line connecting P4 and P7 \\
Truss element & L & Line connecting P5 and P6 \\
Truss element & M & Line connecting P6 and P7 \\
Truss element & N & Line connecting P6 and P8 \\
Truss element & O & Line connecting P7 and P8 \\
\hline
\end{tabular}


Appendix 4: Contact name and affiliation of organizations contacted during investigation for potential sources of river lamprey specimens.

\begin{tabular}{|c|c|}
\hline Contact name & Organization \\
\hline Bashman, Larry & Fish Passage Center, Portland, Oregon \\
\hline Beamish, Richard & Canadian Department of Fisheries and Oceans \\
\hline Bond, Carl & Oregon State University \\
\hline Crane, Pat & Lower Elwha Klallam Tribe \\
\hline Docker, Margret & University of Windsor, Ontario, Canada \\
\hline Goodwin, Kevin & Oregon State University, Hatfield Marine Science Center \\
\hline Haas, Gordon & University of Alaska Fairbanks \\
\hline Hinton, Sue & National Oceanic and Atmospheric Administration Fisheries Service \\
\hline Jacobs, Steve & Oregon Department of Fish and Wildlife, Corvallis \\
\hline Johnson, Thom & Point No Point Treaty Council \\
\hline Loomis, Dave & Oregon Department of Fish and Wildlife, Roseburg \\
\hline Mallat, Jon & Washington State University \\
\hline Markle, Doug & Oregon State University \\
\hline McCosker, John & Steinhart Aquarium \\
\hline McRay, Gene & Oregon State University, Hatfield Marine Science Center \\
\hline Mongillo, Paul & Washington Department of Fish and Wildlife \\
\hline Niemi, Dan & Washington Department of Fish and Wildlife, Fish Collection Facility \\
\hline Parkenson, Eric & University of British Columbia \\
\hline Rice, Casey & National Oceanic and Atmospheric Administration Fisheries Service \\
\hline Rien, Tom & Oregon Department of Fish and Wildlife \\
\hline Smith, Mysi & Steinhart Aquarium \\
\hline Sutherland, Bruce & Lower Columbia River Estuary Program \\
\hline Thompson, Terry & Association of Trawlers \\
\hline Tinus, Eric & Oregon Department of Fish and Wildlife \\
\hline Tucker, Tom & Monterey Bay Aquarium \\
\hline Urbain, Brian & University of Washington \\
\hline Van der Wetering, Stan & Confederated Tribes of the Siletz Indian Reservation \\
\hline Weinheimer, John & Washington Department of Fish and Wildlife \\
\hline
\end{tabular}

